\title{
Study on Mining Pressure Control of Deep Coal Seam--Based on Artificial Fault Technology
}

\section{Xiaoding Xu ( $\square$ ding_xu@cumt.edu.cn )}

Jilin University

\section{Yubing Gao}

China University of Mining and Technology

Manchao He

China University of Mining and Technology

\section{Qiang Fu}

China University of Mining and Technology

\section{Xingjian Wei}

China University of Mining and Technology

\section{Research Article}

Keywords: Mining pressure, artificial fault, concentrated stress, pressure transfer

Posted Date: March 23rd, 2021

DOl: https://doi.org/10.21203/rs.3.rs-333799/v1

License: (c) (1) This work is licensed under a Creative Commons Attribution 4.0 International License. Read Full License 
Xiaoding $\mathrm{Xu}^{\mathrm{a}, \mathrm{b}, *, \dagger}$, Yubing Gao ${ }^{\mathrm{b},{ }^{,}, \dagger}$, Manchao $\mathrm{He}^{\mathrm{a}, \mathrm{b}}$, Qiang Fu ${ }^{\mathrm{b}}$, Xingjian Wei ${ }^{\mathrm{b}}$

${ }^{a}$ College of Construction Engineering, Jilin University, Changchun 130026, China

${ }^{b}$ State Key Laboratory for Geomechanics \& Deep Underground Engineering Beijing, China University of Mining \& Technology, Beijing 100083, China

*Correspondence:yubing.gao@yahoo.com(Y.b Gao), ding_xu@cumt.edu.cn (X.d Xu);

+ All authors contributed equally to this work.

Abstract: Based on the pressure transfer principle and stress distribution characteristics around a fault, introducing artificial fault technology to control the propagation of abutment pressure, and a mechanical model of abutment pressure under the influence of artificial fault was established. This new mechanical model can well fit the distribution law of mining stress after roof cutting. The pressure transfer mechanism of prefabrication support of rock blasting was analyzed, and the transfer trend of pressure and the mining stress of rock top was determined. It is of great significance to guide the implementation of the pressure relief work at the top of the stope. The study shows that the total energy of the system is conserved, the integrity of rock layer is destroyed by blasting, and the deformation and damage of pressure relief zone absorb a large amount of energy. Thus, the accumulated strain energy of abutment pressure region is released, and the influencing range of abutment pressure is reduced. As the horizontal distance from the cutting surface is farther away from the working surface, the smaller the stress difference on both sides of the cutting top, the less obvious the blocking effect of mining pressure. When the cutting point is closer to the working surface, the higher the peak value of abutment pressure due to the superposition of peripheral stress concentration caused by the cutting and peak of abutment pressure caused by mining. Then, the numerical simulation analysis was carried out, the results show that the technology of forming artificial fault by cutting the top can cut off the influence range of the mining pressure. It can effectively control the deformation of dynamic pressure tunnl. Finally, a practice of rock blasting pressure relief engineering was carried out, and the influencing range of abutment pressure of working face before blasting pressure reduction was reduced by $1 / 3$ compared with that before the pressure relief.

Keywords: Mining pressure; artificial fault; concentrated stress; pressure transfer. 


\section{Introduction}

Mining pressure originates from the redistribution of stress caused by the movement of overlying strata in the mining face after coal seam mining. The key layer theory states that when the overlying strata are thicker and the rock stratum is harder, it can be overlaid [Qian et al.(2010), He et al.(2005), Guo (2018), Grady and Kipp (1987), Taylor et al. (1986), Kuszmaul (1987), Throne (1990), Gao (2013)]. In the rock stratum, the key layer plays the role of the main body. At this time, the influencing range of the abutment pressure is obviously increased. When the tunnel is close to the stoppage line and the coal pillar of retaining lane is insufficiently reserved, the abutment pressure and rock stratum are broken. The occurrence of Mining pressure will cause stress disturbance to the tunnel in front of the working face, leading to a large deformation of the tunnel [Li et al.(2012), Meng et al. (2016), Wang et al. (2008), Zhang et al. (2012), Zhang et al. (2016), Zhang et al. (2011), Jiang et al. (2016), Zhang et al. (2017), Xu et al. (2019)]. Therefore, it is especially important to control the range of dynamic pressure. In this study, a new method was developed to control the influencing range of mining pressure by cutting the top pressure relief structure.

Chinese scholars have also carried out extensive studies on stress distribution around the fractured zone. Liu and Zhang (2013) combined the theory of top-loading pressure relief with the actual production of underground mines to solve the problem of surrounding rock instability in the mining tunnel after the coal pillars are left behind. Good control of deformation instability of mining tunnel was achieved. Pu and Zhang (2014) used the top-loading pressure relief technology in the downhole to reduce the overburden pressure on the tunnel along the gob, so that the deformation of tunnel was well controlled. Wan et al. (2014) proposed precracking and reported that a combination of high-strength and high-preloading anchor cables could successfully strengthen the support to protect the tunnel along the road at the scene. Wang et al. (2014) and others conducted theoretical analysis and optimization of deep hole precracking and pressure-relief related construction of roof and solved the problems of large deformation of surrounding rock in a coal seam tunnel difficult to maintain and difficult to replace. Tang and Sheng (2015) and others solved problems in a special production environment of multi coal mining in coal mines when the deformation of surrounding rock of tunnel is large. They proposed to use presplitting and then cut the transmission between overburden pressures to reduce the pressure of tunnel. A test was carried 
out on site, and the remaining tunnel was cut due to the pressure transmission mechanism, so that the deformation amount was significantly reduced. Chen et al. (2015) used LS-DYNA simulation software to theoretically deduce the effect of guide hole on a deep-hole precracked roof under the condition of hard overburden in a thick coal seam. The test data surface was extracted from the hole to the deep hole. The cracking effect is better and can be promoted appropriately. Based on the idea of cutting off pressure transmission on the roof of coal seam, He et al. (2017) proposed the "110 method," i.e., roof precracking was carried out at a certain angle by covering the rock layer in the mining trough, and the constant resistance was high. The tightening anchor cable improves the support strength of mining tunnel, successfully protects the mining and smoothing groove, and shows the application of automatic coal pillar-free technology in the field.

Meng et al (2006) used mechanical tests and numerical simulation methods to evaluate the effect of normal faults on working face pressure. This study shows that with a close distance of working face from the fault, the abutment pressure of working face is obviously increased, and the support is supported. The stress peak is present between the working surface and fault. Yu and Xie (1998) studied the effect of geometry of fault plane on its activation characteristics based on fractal theory. A numerical software was used to analyze the stress distribution around the fault plane of different fractal features. Li et al. (2010) established a mechanical model for fault and rockburst induced prediction, studied the mechanism of fault-type rockburst occurrence, and analyzed the effects of different stress states on the occurrence of fault-type rock pressure. Li et al. (1982) conducted a ground stress test on the North China Sea faults by onsite measurement. It was found that the principal stress directions remained unchanged at different distances, but the principal stress values were quite different. Ding et al. (1981) measured the in-situ stress of a fault in Yunnan; the results show that the principal stress direction around the fault is consistent with the fault strike. Su (2002) used numerical simulation to study the effects of friction angle, cohesion, and rock stiffness on the stress distribution around a fault. The study shows the effect of internal friction angle of rock mass on the stress distribution around the fault.

The large deformation of tunnel has always been a big problem in mine support work. At present, the main treatment methods for tunnel include the enhanced surrounding rock support strength method, tunnel deep hole relief pressure tank method, tunnel surrounding rock blasting pressure relief. These methods do not cut off the propagation path of mining load from the root source, nor change the stress distribution law at the far end. Therefore, this study focuses on the 
mechanism of rock mass blasting and topping pressure relief and determines the stress distribution of leading bearing after pressure relief.

\section{Engineering background}

The average depth of 14200 working face of Pingdingshan Coal Mine is $625 \mathrm{~m}$; the average slope width is $173.5 \mathrm{~m}$; the average coal thickness is $2.0 \mathrm{~m}$; the area is $295175 \mathrm{~m}^{2}$; the bulk density is 1.4 tons $/ \mathrm{m}^{3}$. The dynamic pressure affects the tunnel is located $100 \mathrm{~m}$ in front of the original stop line of 14200 working face and in the mudstone $15 \mathrm{~m}$ above the coal seam. When the coal seam is redistributed after the mining, the weight of overburden layer in the original coal seam shifts to the periphery, thus increasing the abutment pressure above the working face. The overall trend is that the abutment pressure of working face is small, and the pressure is within the distance of working face. When the abutment pressure reaches its peak value, the elevated zone decreases rapidly and reaches the original rock stress as the distance increases, as shown in Fig. 1. Because of the effect of main key layer of $30 \mathrm{~m}$ thick at $80 \mathrm{~m}$ above the coal seam, the effect of abutment pressure on the working face is $100 \mathrm{~m}$, which causes the tunnel to deform greatly, as shown in Fig. 2. .

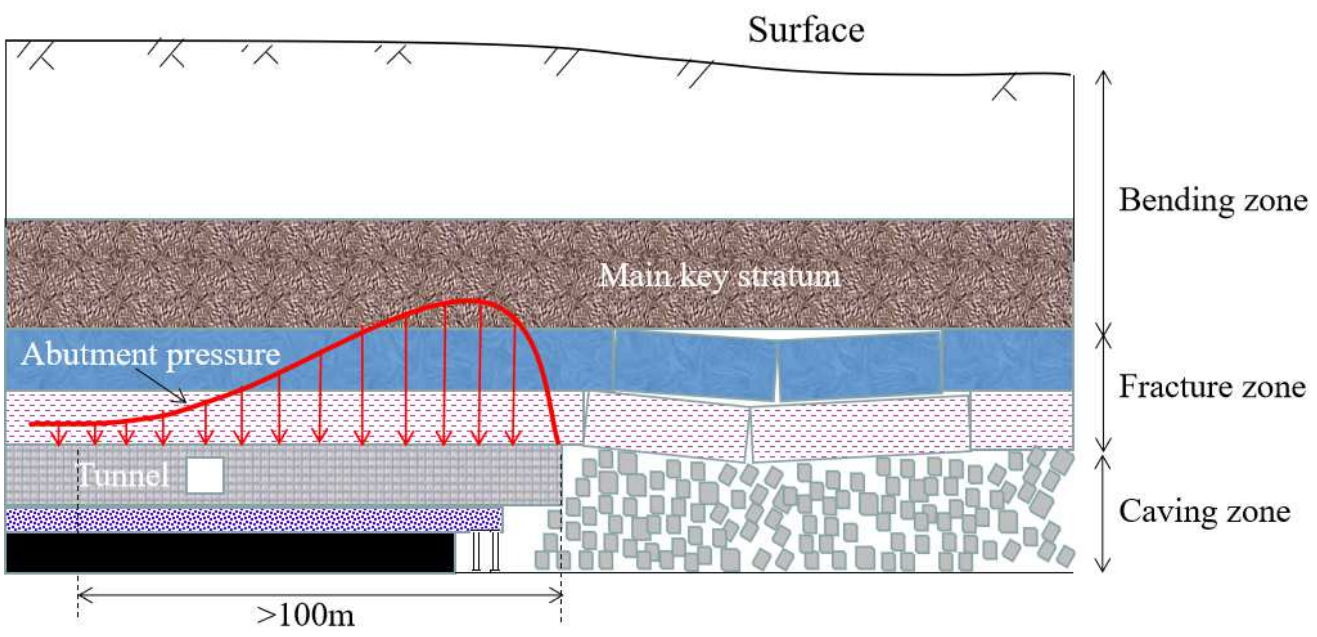

Fig.1. General information of the working face 

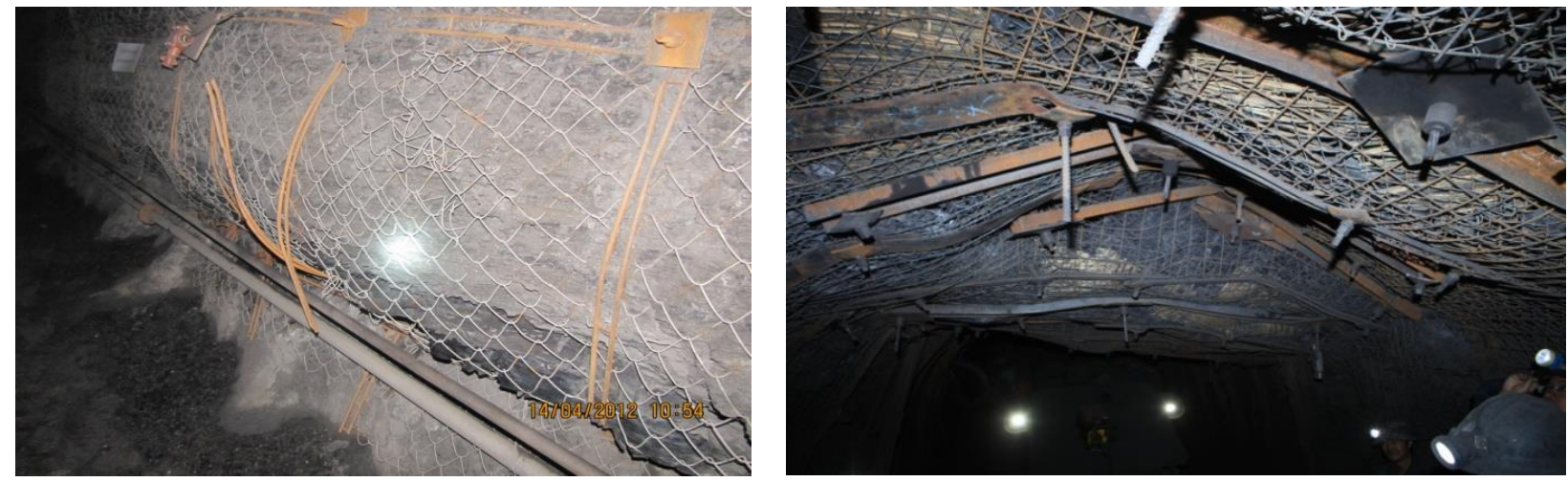

Fig.2. Tunnel deformation under dynamic pressure

disturbance of tunnel. Therefore, the formulation of a governing method is the key to analyze the basis of stress distribution law of stope. To control the deformation of tunnel from the root source, this study proposes a deep hole blasting top-loading pressure relief technology for rock formation, which uses the cavity formed by blasting and the deformation of fracture zone to absorb the high stress energy to reduce the influencing range of abutment pressure, thereby reducing the stress concentration around the tunnel.

\section{Analysis of principle of pressure transfer in blasting and cutting}

After rock blasting, the integrity of rock stratum is destroyed, and a blasting cavity and fracture zone are formed in the rock stratum. The effect is similar to that of nonfalling fault. Because of the fault rupture zone, the coal rock mass is relatively broken with the effect of stress relief and fracture. The stress unloading at the belt causes the stress distribution of leading working face to shift, thereby acting as a pressure relief to reduce the influencing range of stress. The pressure transfer mechanism can be analyzed using energy theory. Because the total energy of rock mass is composed of rock mass fracture energy and strain energy is accumulated in the rock body, according to the law of conservation of power:

$$
f=W_{c}+W_{d}
$$

where $f$ is the total energy of system; $W_{c}$ is the strain energy reaccumulated by the rock mass after the coal seam is opened; $W_{d}$ is the strain energy absorbed by various forms such as deformation and failure of rock mass.

Eq. (1) shows that the abutment pressure at each point of rock layer can be reduced by 
reducing the accumulated strain energy $W_{c}$ at each point. Because the total energy of the system is constant, to lower the $W_{c}$ value, the $W_{d}$ value should be increased. Increasing $W_{d}$ means increasing the deformation and damage of rock mass within a certain range. The principle of blasting pressure relief is to form some broken and cracked areas in the overburden species, so that the deformation absorbs a large amount of energy and increases the $W_{d}$.

At the same time, after rock blasting, the integrity of rock stratum is destroyed, and a blasting cavity and fracture zone are formed in the rock stratum. The effect is similar to artificial fault. Therefore, the blasting can be analyzed using the prestressed stress distribution law under the effect of faults. The distribution law of abutment pressure after the topping was determined, as shown in Fig. 3. The fault fracture zone concentrates the surrounding stress, concentrates the high-end stress on both sides of fault, and reduces the distal stress, so that the influencing range of abutment pressure is shortened.

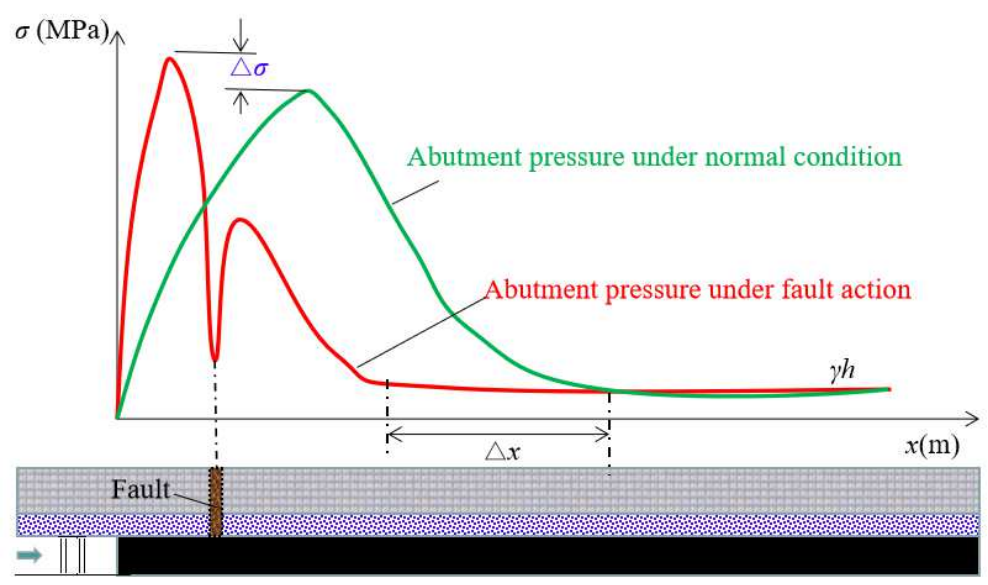

Fig.3. Diagram of stress distribution under the influence of faults

\section{Pressure distribution model of strata with artificial faults}

\subsection{Mechanical model of stress distribution of abutment pressure before cutting}

With reference to the solution to the plane problems as to the action of concentrated force on semi-infinite body in elasticity theory, a calculation model of vertical stress formed by load in a semi elastomer can be established, as shown in Fig. 4. 


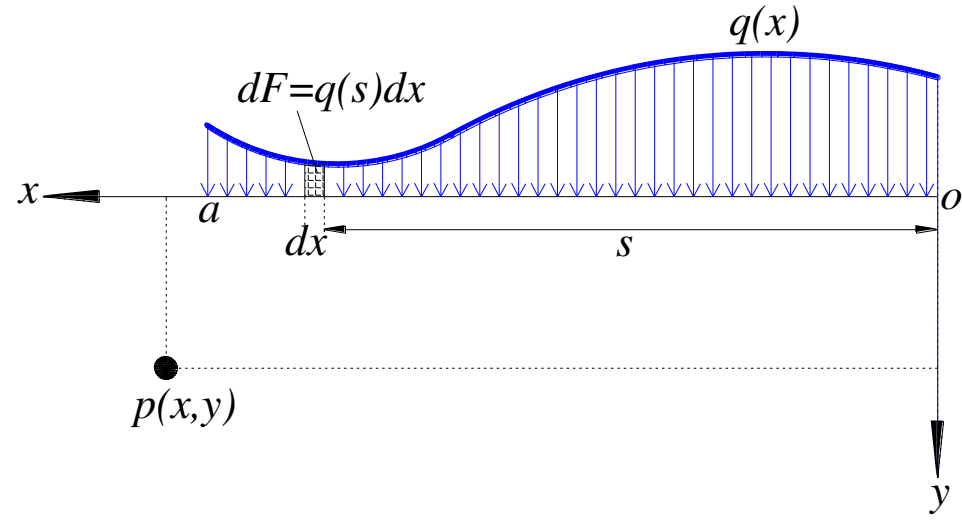

Where $d s$ is the unit length $s$ away from the $O$ point, then the force per unit length can be approximated as the concentrated force, $d F=q(s) d x$. According to the knowledge of elastic mechanics, the stress at any point of the semi-infinite body under the concentrated force can be solved, and combined with the mathematical integration algorithm, the stress at any point in the semi-infinite body under the load $q(x)$ can be obtained as follows:

$$
\left\{\begin{array}{l}
\sigma_{y}=\frac{2}{\pi} \int_{0}^{a} \frac{q(x) y^{3}}{\left[y^{2}+(x-s)^{2}\right]^{2}} d s \\
\sigma_{x}=\frac{2}{\pi} \int_{0}^{a} \frac{q(x)(x-s)^{2} y}{\left[y^{2}+(x-s)^{2}\right]^{2}} d s \\
\tau_{z x}=\frac{2}{\pi} \int_{0}^{a} \frac{q(x)(x-s) y^{2}}{\left[y^{2}+(x-s)^{2}\right]^{2}} d s
\end{array}\right.
$$

Model assumptions:

1) The overlying rock mass of coal seam is a uniform elastic isotropic material.

2) Longwall mining is considered as a plane strain problem along the direction of advancement of working face.

According to the characteristics and assumptions of prestressed bearing stress distribution curve of mining face, a calculation model was established for the bearing stress arbitrary point, as shown in Fig. 5. According to the simplified abutment pressure curve, it can be divided into three sections: ab section, bc section, and cd section, and the upper stress function of each section can be obtained using the force geometric similarity theory. 


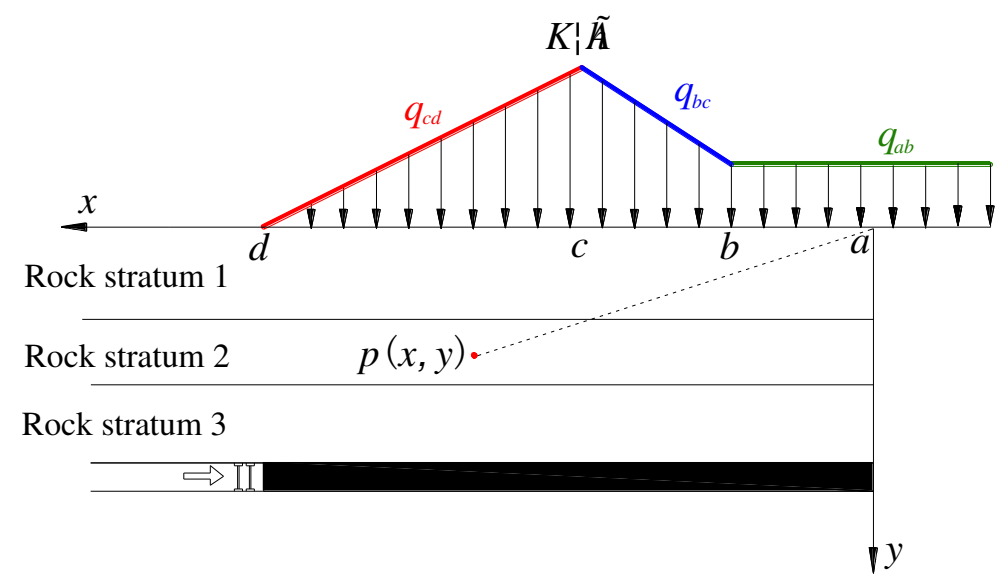

Section $b c$ :

$$
q_{b c}(x)=\frac{(K-1) \gamma h}{x_{c}-x_{b}}\left(x-x_{b}\right)+\gamma h
$$

Section $a b$ :

$$
q_{a b}(x)=\gamma h
$$

Section $c d$ :

$$
q_{c d}(x)=\frac{K \gamma h}{x_{d}-x_{c}}\left(x_{d}-x\right)
$$

The vertical stress of each point on half-face can be obtained according to the theory of arbitrary point force calculation of elastic mechanics.

When $s \in\left(-\infty, x_{b}\right)$, the vertical stress of ab segment load at any point of hemisphere can be expressed as follows:

$$
\sigma_{a b}(x, y)=\frac{\gamma h y\left(x_{b}-x\right)}{\pi\left[y^{2}+\left(x-x_{b}\right)^{2}\right]}+\frac{\gamma h}{\pi} \arctan \left(\frac{x_{b}-x}{y}\right)+\frac{1}{2} \gamma h
$$

192

When $s \in\left(x_{b}, x_{c}\right)$, the vertical stress of $b c$ segment load at any point of hemisphere can be expressed as follows:

$$
\sigma_{b c}(x, y)=\left.\left\{\begin{array}{l}
\frac{\gamma h y\left[\left(K\left(x-x_{b}\right)+x_{c}-x\right) s+\left(x_{b}(K-1)-x_{c}+x_{b}\right) x-(K-1)\left(x^{2}+y^{2}\right)\right]}{\pi\left(x_{c}-x_{b}\right)\left(y^{2}+(x-s)^{2}\right)} \\
+\frac{\gamma h y}{\pi\left(x_{c}-x_{b}\right)}\left(K\left(x-x_{b}\right)+x_{c}-x\right) \arctan \left(\frac{s-x}{y}\right)
\end{array}\right\}\right|_{x_{b}} ^{x_{c}}
$$

When $s \in\left(x_{c}, x_{d}\right)$, the vertical stress of $c d$ segment load at any point of hemisphere can be expressed as follows: 


$$
\sigma_{c d}(x, y)=\left.\left\{\frac{K \gamma h y\left(x^{2}+y^{2}-x s+(s-x) x_{d}\right)}{\pi\left(x_{d}-x_{c}\right)\left(y^{2}+(x-s)^{2}\right)}+\frac{K \gamma h y\left(x_{d}-x\right)}{\pi\left(x_{d}-x_{c}\right)} \arctan \left(\frac{s-x}{y}\right)\right\}\right|_{x_{c}} ^{x_{d}}
$$

After superimposing the vertical stresses of each load using the principle of stress superposition, The vertical stress at any point produced by the whole load can be obtained as follows:

$$
\begin{aligned}
& \sigma_{y}(x, y)=\frac{\gamma h y\left(x_{b}-x\right)}{\pi\left[y^{2}+\left(x-x_{b}\right)^{2}\right]}+\frac{\gamma h}{\pi} \arctan \left(\frac{x_{b}-x}{y}\right)+\frac{1}{2} \gamma h \\
& +\left.\left\{\begin{array}{l}
\left.\frac{\gamma h y\left[\left(K\left(x-x_{b}\right)+x_{c}-x\right) s+\left(x_{b}(K-1)-x_{c}+x_{b}\right) x-(K-1)\left(x^{2}+y^{2}\right)\right]}{\pi\left(x_{c}-x_{b}\right)\left(y^{2}+(x-s)^{2}\right)}\right]\left.\right|^{x_{c}} \\
+\frac{\gamma h y}{\pi\left(x_{c}-x_{b}\right)}\left(K\left(x-x_{b}\right)+x_{c}-x\right) \arctan \left(\frac{s-x}{y}\right)
\end{array}\right\}\right|_{x_{b}} \\
& +\left.\left\{\frac{K \gamma h y\left(x^{2}+y^{2}-x s+(s-x) x_{d}\right)}{\pi\left(x_{d}-x_{c}\right)\left(y^{2}+(x-s)^{2}\right)}+\frac{K \gamma h y\left(x_{d}-x\right)}{\pi\left(x_{d}-x_{c}\right)} \arctan \left(\frac{s-x}{y}\right)\right)\right|_{x_{c}} ^{x_{d}}
\end{aligned}
$$

Because of the rupture of rock mass after the blasting pressure, the elastic half-plane theory cannot be used directly to solve the stress state of rock layer after blasting. However, the fracture zone obtained after blasting pressure relief is similar to the fault-free fault, so the theory of elastic hemisphere can be used. Combined with the stress distribution theory of fault zone and the principle of stress superposition, the distribution of abutment pressure after blasting pressure relief can be solved.

\subsection{Mechanical model of stress distribution in abutment pressure after cutting}

Based on the stress distribution characteristics on both sides of fault-free fault zone, a stress distribution mechanical model was constructed on both sides of pressure-relief belt (artificial fault). Let $k$ be the stress attenuation coefficient at the lowest point of stress reduction zone, $k^{\prime}$ be the concentration coefficient of peak stress in the stress-increasing zone, and $q$ is the original stress. The rock stress and stress of each section are linearly distributed. The center point of pressure relief zone is the minimum stress kq of the stress reduction zone, and the peak stress of stress zone is $k^{\prime} q$, as shown in Fig. 6. 


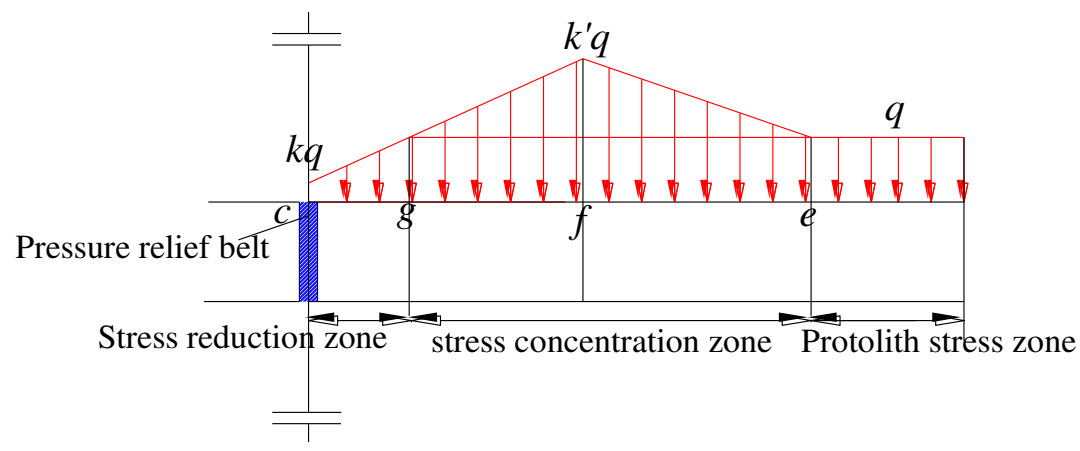

Fig.6. Mechanical model of stress distribution on both sides of artificial fault

Model assumptions:

1) The overlying rock mass of coal seam is a uniform elastic isotropic material.

2) The medium in pressure relief belt is a completely elastic material.

3) The width of pressure relief belt is negligible compared to a large range of rock mass.

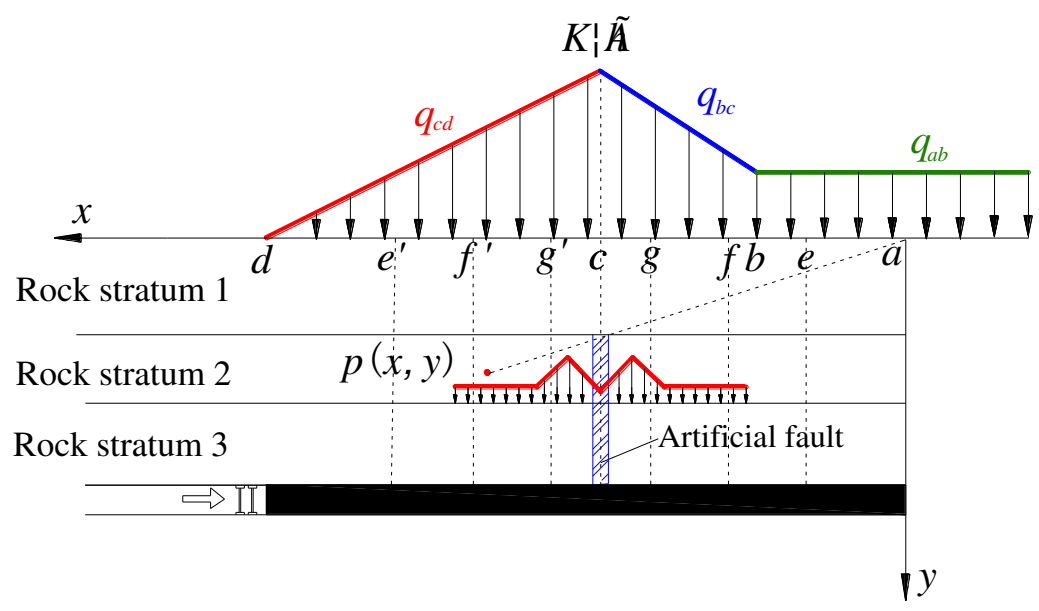

Fig.7. Calculation model of arbitrary point force of bearing stress with artificial fault

Based on the stress redistribution characteristics on both sides of artificial fault and the analytical solution of abutment pressure under the unloading state, the distribution law of lead abutment pressure after pressure relief can be obtained. As shown in Fig. 7, the overburden after demolition and blasting can be divided into two large areas: the blasting pressure relief zone ( $e^{\prime} e m n$ zone) and the nonblasting pressure relief zone. The influence area of blasting pressure relief is affected by the stress zones in Fig. 4 and Fig. 5 at the same time, so it can be divided into four zones, namely, $c-f$ zone (Zone 1), c-f' zone (Zone 2), b-e zone (Zone 3), and $b^{\prime}-e^{\prime}$ zone (Zone 4). The stress of four regions can be solved by equation (9) in combination with Fig. 6.

The distributed stress in the $c-f$ zone (Zone 1) of blasting pressure relief zone can be calculated 
as follows:

236

237

238

Blasting pressure relief affects the distribution stress calculation in Zone 2 as follows:

$$
\left\{\begin{array}{l}
\sigma_{2}(x, y)=\sigma_{y}+\frac{\sigma_{y}\left(k^{\prime}-1\right)\left(x-x_{e}\right)}{x_{f}-x_{e}} \\
x \in\left(x_{e}, x_{f}\right), y \in\left(y_{m}, y_{n}\right)
\end{array}\right.
$$

Blasting pressure relief affects the distribution stress calculation in Zone 3 as follows:

$$
\left\{\begin{array}{l}
\sigma_{3}(x, y)=k^{\prime} \sigma_{y}+\frac{\sigma_{y}\left(k^{\prime}-k\right)\left(x-x_{f^{\prime}}\right)}{x_{f^{\prime}}-x_{e^{\prime}}} \\
x \in\left(x_{c}, x_{f^{\prime}}\right), y \in\left(y_{m}, y_{n}\right)
\end{array}\right.
$$

Blasting pressure relief affects the distribution stress calculation in Zone 4 as follows:

$$
\left\{\begin{array}{l}
\sigma_{4}(x, y)=k^{\prime} \sigma_{y}+\frac{\sigma_{y}\left(k^{\prime}-1\right)\left(x-x_{f^{\prime}}\right)}{x_{f^{\prime}}-x_{e^{\prime}}} \\
x \in\left(x_{f^{\prime}}, x_{e^{\prime}}\right), y \in\left(y_{m}, y_{n}\right)
\end{array}\right.
$$

In summary, an analytical formula for the distribution after the demolition of rock blasting can be expressed as follows:

$$
\begin{cases}\sigma_{1}(x, y)=k \sigma_{y}+\frac{\sigma\left(k^{\prime}-k\right)\left(x-x_{f}\right)}{x_{c}-x_{f}} & x \in\left(x_{f}, x_{c}\right) \\ \sigma_{2}(x, y)=\sigma_{y}+\frac{\sigma_{y}\left(k^{\prime}-1\right)\left(x-x_{e}\right)}{x_{f}-x_{e}} & x \in\left(x_{e}, x_{f}\right) \\ \sigma_{3}(x, y)=k^{\prime} \sigma_{y}+\frac{\sigma_{y}\left(k^{\prime}-k\right)\left(x-x_{f^{\prime}}\right)}{x_{f^{\prime}}-x_{e^{\prime}}} & x \in\left(x_{c}, x_{f^{\prime}}\right) \\ \sigma_{4}(x, y)=k^{\prime} \sigma_{y}+\frac{\sigma_{y}\left(k^{\prime}-1\right)\left(x-x_{f^{\prime}}\right)}{x_{f^{\prime}}-x_{e^{\prime}}} & x \in\left(x_{f^{\prime}}, x_{e^{\prime}}\right)\end{cases}
$$

\subsection{Analysis of engineering examples}

Based on the geological conditions of 14200 working face of Pingdingshan No. 8 Mine, the distribution of abutment pressure of coal seam working face under different cutting conditions was calculated. The horizontal distance between the peak point of fracture zone and working face is 10 
$\mathrm{m}$, and the stresses on both sides of peak point are symmetrically distributed. The height of blasting cutting roof is $30 \mathrm{~m}$, and the ranges of stress reduction zone and stress rise zone caused by blasting chopping are both $5 \mathrm{~m}$. The calculation parameters are shown in Table 1.

Tab.1. Working surface abutment pressure calculation parameters

\begin{tabular}{cccccc}
\hline$K$ & $k$ & $k^{\prime}$ & $\gamma / \mathrm{kN} / \mathrm{m}^{3}$ & $h / m$ & $y / m$ \\
\hline 1.5 & 0.6 & 1.1 & 25 & 600 & 30 \\
\hline
\end{tabular}

To study the distribution law of abutment pressure at different pressure relief locations, five calculation schemes were set: horizontal distances of blasting pressure relief belt from the working surface of $10 \mathrm{~m}, 20 \mathrm{~m}, 30 \mathrm{~m}, 40 \mathrm{~m}$, and $50 \mathrm{~m}$. The parameters were substituted into Formula (14). The magnitude of abutment pressure formed by the overburden load in the coal seam can be obtained, and the abutment pressure curve can be obtained after fitting, as shown in Fig. 8.

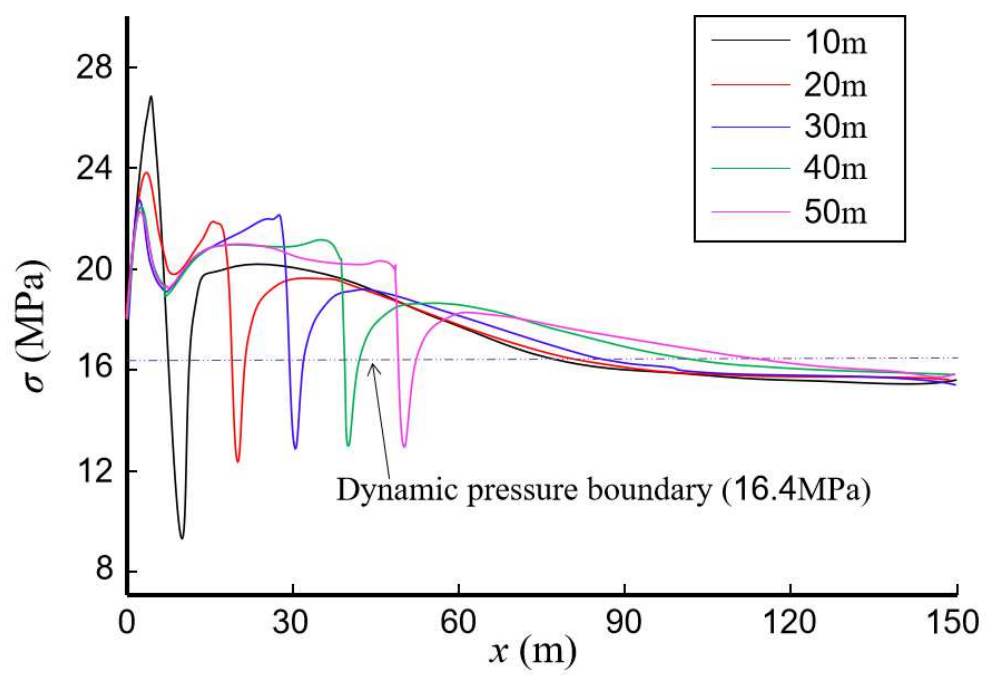

Fig.8. Abutment pressure curves at different horizontal cutting positions from the working face

The buried depth of coal seam is $625 \mathrm{~m}$, and the average weight of overburden is $25 \mathrm{kN} / \mathrm{m}^{3}$. The vertical stress of coal seam was calculated to be $15.6 \mathrm{MPa}$ when not excavated. According to the relevant Mining pressure disturbance theory, it was determined whether it is a significant influencing area by 1.05 times of the stress under the original rock stress state, i.e., $16.4 \mathrm{MPa}$. If the vertical stress is higher than 16.4 MPa, it is considered to be at the working face. Within the scope of influence and vice versa, there is no effect, so a horizontal straight line of $16.4 \mathrm{MPa}$ was added in 
Fig. 8 to measure the dynamic pressure influencing range under different pressure relief positions. Fig. 8 shows that when the cutting top is $10 \mathrm{~m}$ away from the working surface, the stress difference between the two sides of cutting top is $6 \mathrm{MPa}$, and the effect of lead abutment pressure is $80 \mathrm{~m}$. When the cutting point is $20 \mathrm{~m}$ away from the working surface, the stress difference between the two sides of cutting top is $3 \mathrm{MPa}$, and the influencing range of abutment pressure is also $\sim 80 \mathrm{~m}$. When the cutting point is $30 \mathrm{~m}$ away from the working surface, the stress difference between the two sides of cutting roof is $3 \mathrm{MPa}$, and the effect of abutment pressure is $90 \mathrm{~m}$. When the cutting point is $40 \mathrm{~m}$ away from the working surface, the stress difference between the two sides of cutting roof is $\sim 2.5 \mathrm{MPa}$, and the effect of abutment pressure is $105 \mathrm{~m}$. When the cutting point is $50 \mathrm{~m}$ away from the working surface, the stress difference between the two sides of cutting top is $\sim 2 \mathrm{MPa}$, and the effect of abutment pressure is $110 \mathrm{~m}$. In a certain range, the distance from the cutting surface to the working surface is farther, and the top is cut into two halves. The smaller the lateral stress difference, the less obvious the effect of mining pressure blocking. However, from the analysis of abutment pressure peak of working face, the closer the cutting top to the working surface, the higher the peak value of abutment pressure, mainly because of the cutting area. The distortion effect of edges results in peripheral stress concentration.

Based on the above analysis, the mechanical model can be well fitted to the distribution curve of abutment pressure after blasting and cutting, showing the law of pressure transfer of abutment pressure after blasting and cutting and controlling the influencing range of abutment pressure.

\section{Numerical simulation analysis of the pressure relief of the roof}

\subsection{Establishment of the numerical model}

A numerical model is established based on the actual geological and production conditions of the 14200-working face in the Pingba Mine using Flac3D[(Mehravar et al.(2017), Kabwe et al. (2020)],. The coal seam depth is $620 \mathrm{~m}$, and the coal seam is 100 meters from the surface. A $30 \mathrm{~m}$-thick medium-grain sandstone is the key layer approximately $80 \mathrm{~m}$ above the coal seam. The top interface of the model is applied with the equivalent compressive stress of the overburden layer is $\mathrm{P}=13 \mathrm{Mp}$. The overall model size is $440 \mathrm{~m}(\mathrm{X}) \times 320 \mathrm{~m}(\mathrm{Y}) \times 153 \mathrm{~m}(\mathrm{Z})$, a total of 2076800 grids and 2134860 nodes, as shown in Fig. 9. 


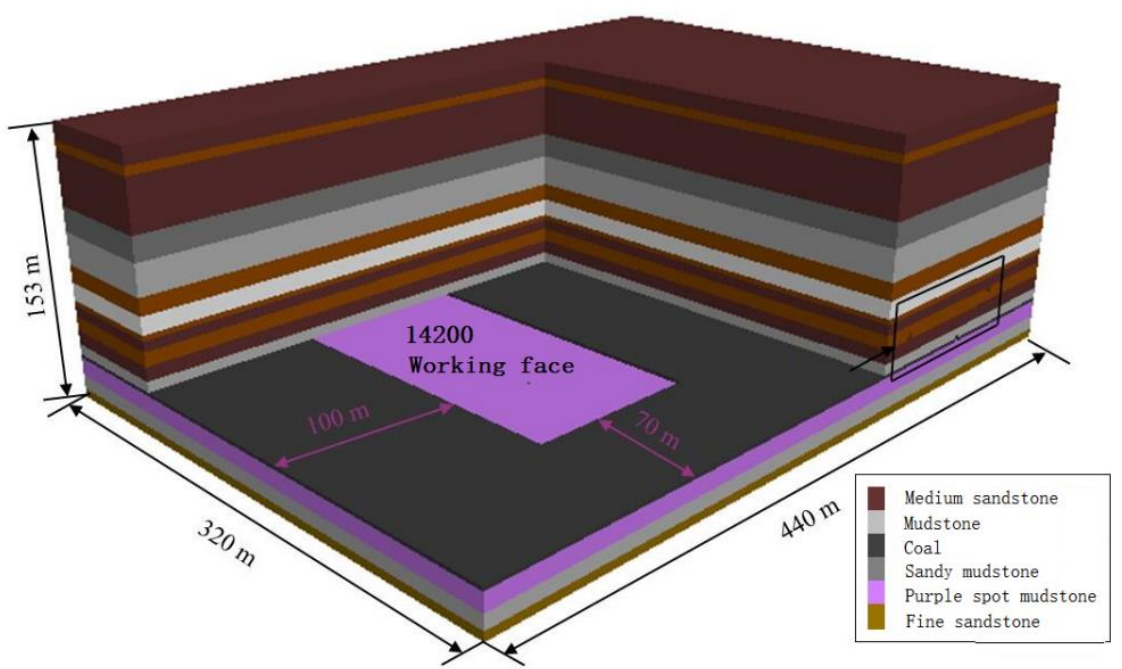

Figure 9 Numerical model of the strata

The rock masses in this simulation are all coal-bearing strata which generally exhibits yield behavior under the shear stress. The Mohr-Coulomb model is selected for the simulation, and the mechanical parameters of the rock mass used in the numerical simulation are shown in Table 2 .

Tab.2 Numerical simulation of physical and mechanical parameters

\begin{tabular}{ccccccc}
\hline $\begin{array}{c}\text { Rock } \\
\text { group } \\
\text { category }\end{array}$ & $\rho / \mathrm{kg}^{2} \cdot \mathrm{m}^{-3}$ & $\mathrm{E} / \mathrm{GPa}$ & $\mathrm{G} / \mathrm{GPa}$ & $c / \mathrm{MPa}$ & $\varphi^{\circ}$ & $\sigma_{\mathrm{t}} / \mathrm{Mpa}$ \\
\hline $\begin{array}{c}\text { Coal } \\
\text { Mudstone } \\
\text { Sandy }\end{array}$ & 1400 & 1.67 & 1.02 & 1.15 & 28 & 1.12 \\
$\begin{array}{c}\text { mudstone } \\
\text { Purple } \\
\text { spot }\end{array}$ & 2200 & 5.00 & 3.00 & 1.52 & 30 & 1.56 \\
$\begin{array}{c}\text { mudstone } \\
\text { Fine }\end{array}$ & 2320 & 9.63 & 6.35 & 3.86 & 32 & 2.36 \\
$\begin{array}{c}\text { sandstone } \\
\text { Middle }\end{array}$ & 2550 & 12.65 & 8.66 & 4.32 & 35 & 2.98 \\
sandstone & 2650 & 3.16 & 1.98 & 3.68 & 38 & 2.65 \\
\hline
\end{tabular}

In the simulation process, setting of weakening parameters of the blasting zone with reference to existing research, the weakening parameters of the blasting zone are: blasting cavity width is $0.2 \mathrm{~m}$; the blasting cavity is set as the center, and an area with a radius of 2 meters is the blasting weakening area (Table 3). 


\begin{tabular}{cccccc}
\hline$\rho / \mathrm{kg} \cdot \mathrm{m}^{-3}$ & $\mathrm{E} / \mathrm{GPa}$ & $\mathrm{G} / \mathrm{GPa}$ & $c / \mathrm{Mpa}$ & $\varphi /^{\circ}$ & $\sigma_{\mathrm{t}} / \mathrm{Mpa}$ \\
\hline 1300 & 0.30 & 0.18 & 0.06 & 6 & 0.15 \\
\hline
\end{tabular}

\subsection{Numerical simulation scheme and result analysis}

In order to analyze the distribution of the mining stress in the face of the work and the deformation of the tunnel, we choose two working conditions for comparative analysis, which are under the condition of no pressure relief and under the condition of roof cutting pressure relief. The simulation solution process is as follows: establish the overall model, calculate the original rock stress balance, form the original in-situ stress field, and open the pressure relief cut seam (pressure relief position: the horizontal distance from the stope line is $15 \mathrm{~m}$, the height of the pressure relief belt is $30 \mathrm{~m}$, and the width of the pressure relief belt is $4 \mathrm{~m}$ ). The working face is mined once with $25 \mathrm{~m}$ as the circulation ring, and excavated four times with a total of $100 \mathrm{~m}$ to make the overlying strata in the goaf fully move, to solve and obtain the vertical stress nephogram in front of the stope line and the vertical stress curve of the coal seam, so as to analyze the influence of the pressure relief position of the roof on the vertical stress in the coal and rock body and the deformation of the tunnel.

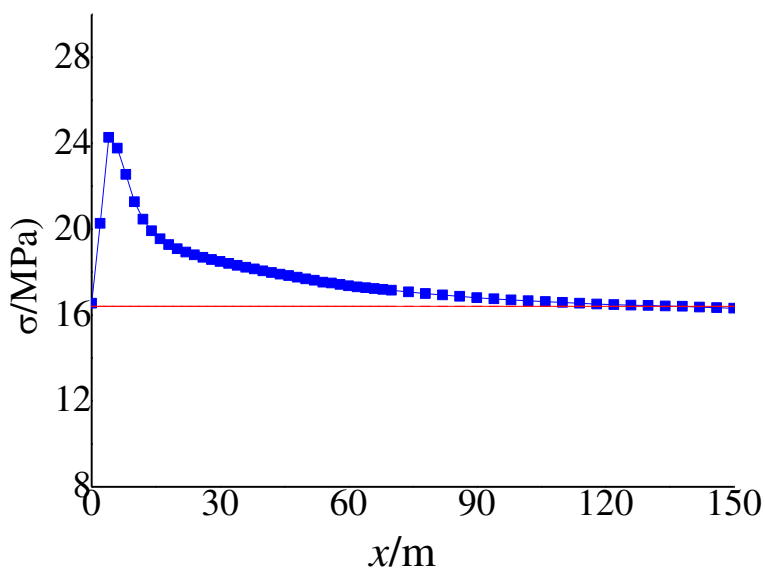

(a) Before unloading

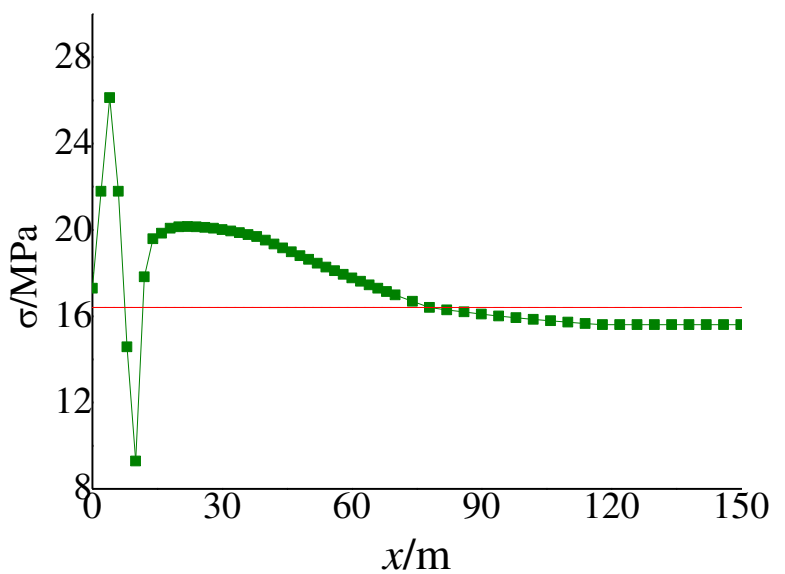

(b) After unloading

Fig. 10 Abutment pressure curve before and after pressure relief

The red horizontal line in Fig.10. is the original rock stress in the case of no mining, so the cross coordinate of the intersection of the abutment pressure curve and the original rock stress line is the influence range of the mining pressure. The comparison between the two figures shows that 
the influence range of mining pressure before pressure relief is about $120 \mathrm{~m}$, the influence range of mining pressure after pressure relief is about $75 \mathrm{~m}$, and the pressure relief shortens the influence range of mining pressure by $45 \mathrm{~m}$, indicating the effectiveness of cutting top pressure relief for blocking load transmission path and shortening the influence range of mining. The result is consistent with the trend of theoretical calculation.

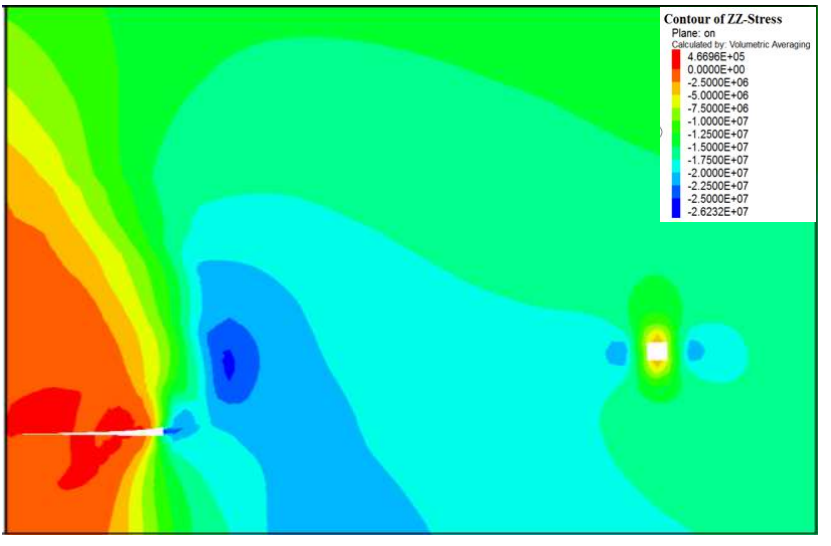

(a) Before unloading

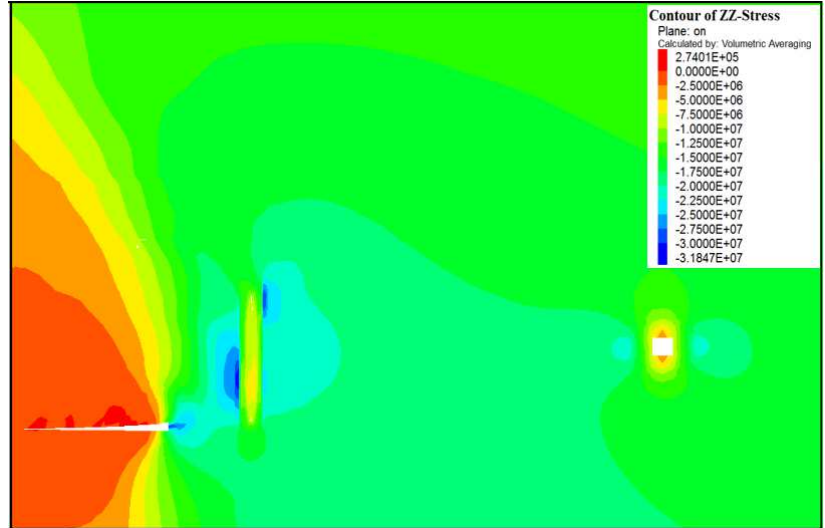

(b) After unloading

Fig. 11 Vertical stress cloud diagram before and after pressure relief

It can be seen from Fig.11. that, compared with the scheme before pressure relief, the peak stress area in front of the coal wall of the working face disappears after pressure relief; after pressure relief, the load transfers to the vicinity of the pressure relief area, and stress concentration occurs on both sides of the pressure relief area. After the pressure relief, the influence range of the advance bearing stress is obviously reduced. Before the pressure relief, the mining advance bearing stress overlaps with the concentrated stress produced by the tunnel excavation. The stress concentration of the two sides of the tunnel is serious. After the pressure relief, the propagation of the advance bearing stress is cut off. The influence range of the advance bearing stress is greatly reduced compared with that before the pressure relief, and the stress concentration around the tunnel disappears.

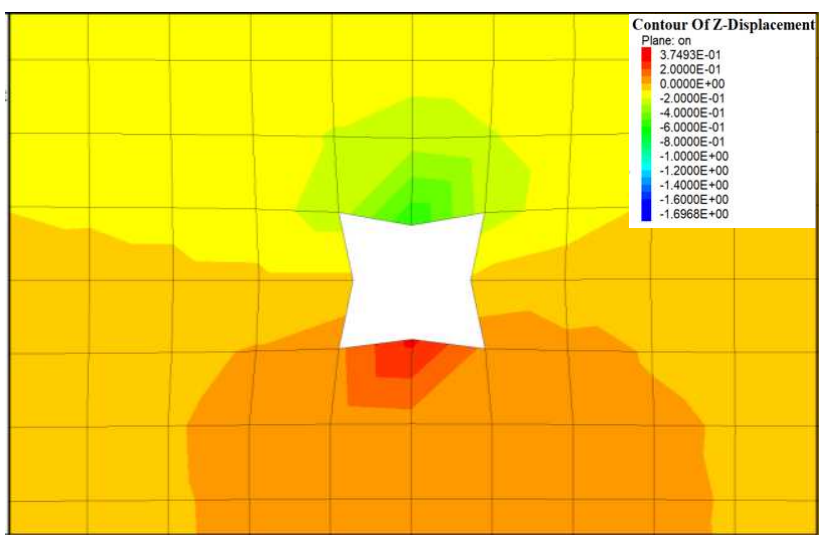

(a) Before unloading

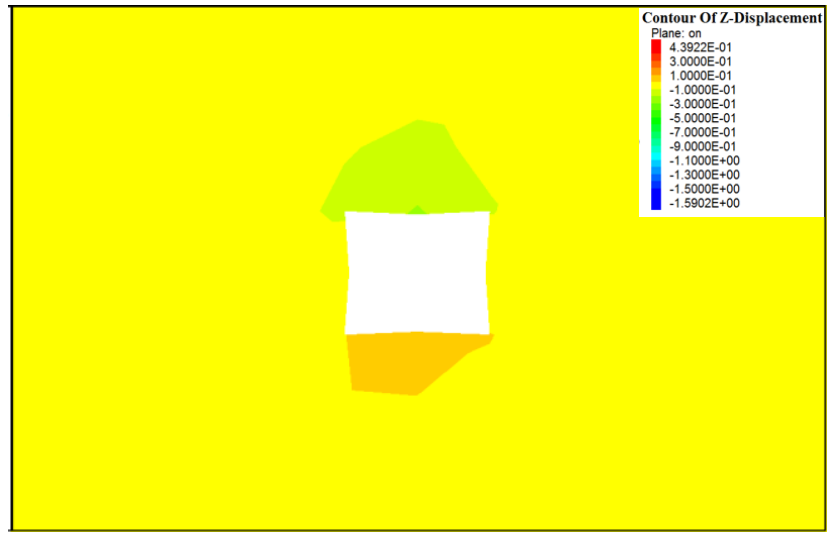

(b) After unloading 
It can be seen from Fig.12. that before the pressure relief, the deformation of the tunnel is large, the roof sinks $32.7 \mathrm{~cm}$, the floor heave is $55.8 \mathrm{~cm}$, the roof and floor displacement reaches $88.4 \mathrm{~cm}$; the deformation of the left side is $50.4 \mathrm{~cm}$, the deformation of the right side is $53.8 \mathrm{~cm}$, and the displacement of the two sides reaches $104.2 \mathrm{~cm}$. After blasting, the deformation of surrounding rock in the tunnel was well controlled. The roof subsidence was $10 \mathrm{~cm}$, the floor heave was $19.7 \mathrm{~cm}$, the roof and floor displacement was $29.7 \mathrm{~cm}, 66.4 \%$ less than before; the left side deformation was $13.5 \mathrm{~cm}$, the right side deformation was $17.9 \mathrm{~cm}$, the two sides displacement was $31.4 \mathrm{~cm}, 69.8 \%$ less than before. Therefore, the deformation of the tunnel in front of the work was effectively controlled by pressure relief.

\section{Rock layer blasting and cutting project practice}

\subsection{Blasting pressure relief area and parameters}

The rationality of blasting pressure relief position directly affects the pressure relief effect. To reduce the influencing range of abutment pressure, the peak value of abutment pressure can be controlled, and the effect on the working surface is reduced. The theoretical analysis result is combined with the cutting position. It should be 10 20 m away from the stop line. Finally, the pressure relief blasting should be carried out $15 \mathrm{~m}$ ahead of the stop line of working face. The blasting drilling arrangement is shown in Fig. 13.

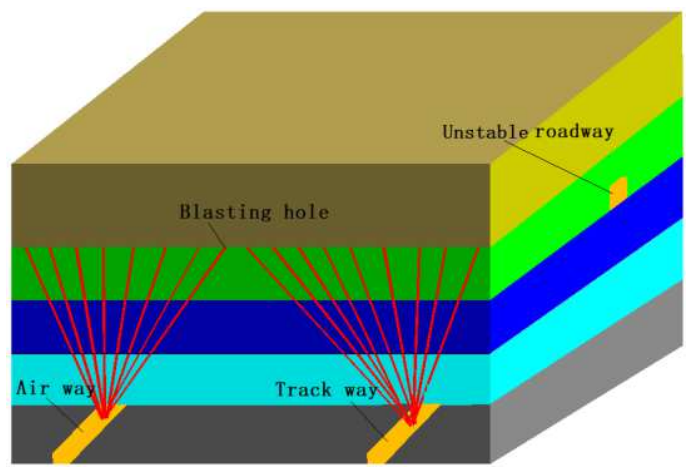

(a) 3D diagram

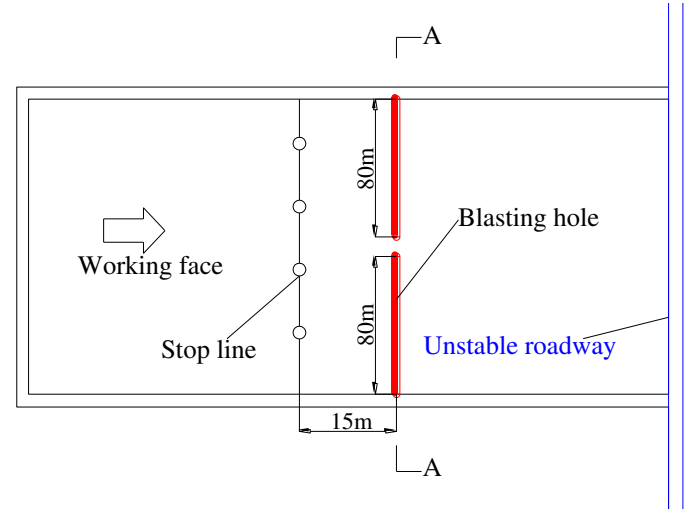

(b) 2D diagram

Fig.13. Layout of blastholes

According to the geological conditions of working area, the lateral length of working face, the 
position of rock formation where the drill is located, the radius of influence of drilled blasting, the spacing of drilling holes, and the height of pressure relief, the drilling of working face can be designed as follows: In the noodle machine lane and wind lane, a set of oblique upward-penetrating boreholes are arranged $15 \mathrm{~m}$ away from the stoppage line, which is fan-shaped, as shown in Fig. 14. The borehole lengths are $85 \mathrm{~m}, 65 \mathrm{~m}, 86 \mathrm{~m}, 70 \mathrm{~m}, 58 \mathrm{~m}, 48 \mathrm{~m}, 40 \mathrm{~m}, 35 \mathrm{~m}$, and $30 \mathrm{~m}$, and the angles with the coal seam are $10^{\circ}, 15^{\circ}, 20^{\circ}, 26^{\circ}, 30^{\circ}, 38^{\circ}, 45^{\circ}, 57^{\circ}$, and $69^{\circ}$, a total of nine holes; three green holes among them are explosive-free control holes.

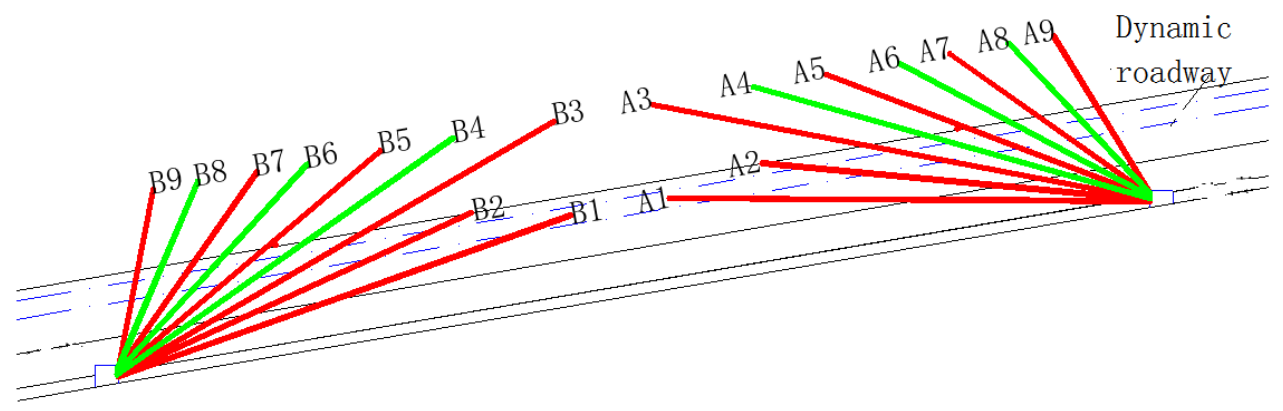

Fig.14. A-A section

Coal mine three-stage emulsion explosives $\left(45^{*} 400 \mathrm{~mm} /\right.$ volume, $440 \mathrm{~g} /$ volume $)$ were used. A millisecond delay electric detonator was used to detonate the explosives. Single-hole detonators were connected in series, and the holes were connected in series with the holes. Positive blasting was used, the bottom of hole was charged, and the outer mouth was sealed with yellow mud. The length of sealing mud is not less than one third of length of hole.

Tab.4 Charge parameters of blasthole

\begin{tabular}{c|cccc}
\hline Number & Hole depth / $\mathrm{m}$ & Angle $/{ }^{\circ}$ & $\begin{array}{c}\text { Explosive } \\
\text { length } / \mathrm{m}\end{array}$ & Sealing length / $\mathrm{m}$ \\
\hline A1 & 85 & 10 & 30 & 55 \\
A2 & 65 & 15 & 30 & 35 \\
A3 & 86 & 20 & 30 & 56 \\
A4 & 70 & 26 & 0 & 3 \\
A5 & 58 & 30 & 30 & 28 \\
A6 & 48 & 38 & 0 & 3 \\
A7 & 40 & 45 & 25 & 15 \\
A8 & 35 & 57 & 0 & 3 \\
A9 & 30 & 69 & 15 & 15 \\
B1 & 85 & 10 & 30 & 55 \\
B2 & 65 & 15 & 30 & 35 \\
B3 & 86 & 20 & 30 & 56 \\
B4 & 70 & 26 & 0 & 3
\end{tabular}




\begin{tabular}{c|cccc} 
B5 & 58 & 30 & 30 & 28 \\
B6 & 48 & 38 & 0 & 3 \\
B7 & 40 & 45 & 25 & 15 \\
B8 & 35 & 57 & 0 & 3 \\
B9 & 30 & 69 & 15 & 15 \\
\hline
\end{tabular}

397

398

399

400

401

402

403

404

405

406

\subsection{Monitoring plan and analysis}

\subsubsection{Monitoring plan}

(1) Monitoring of artificial fault

The method of ultrasonic detection is used to monitor the artificial fault formed by blasting, assisting inthe side of the dynamic pressure roadway, receiving the same, and doing reflection wave exploration, the monitoring instrument is shown in Fig.15. The monitoring spots were set on the side of the roadway. There were 12 receiving spots set up with a spacing of $12 \mathrm{~m}$, and the excitation point was located in the middle of the receiving point; the total length of the monitoring line was approximately $144 \mathrm{~m}$. The monitoring point arrangement is shown in Fig.16.

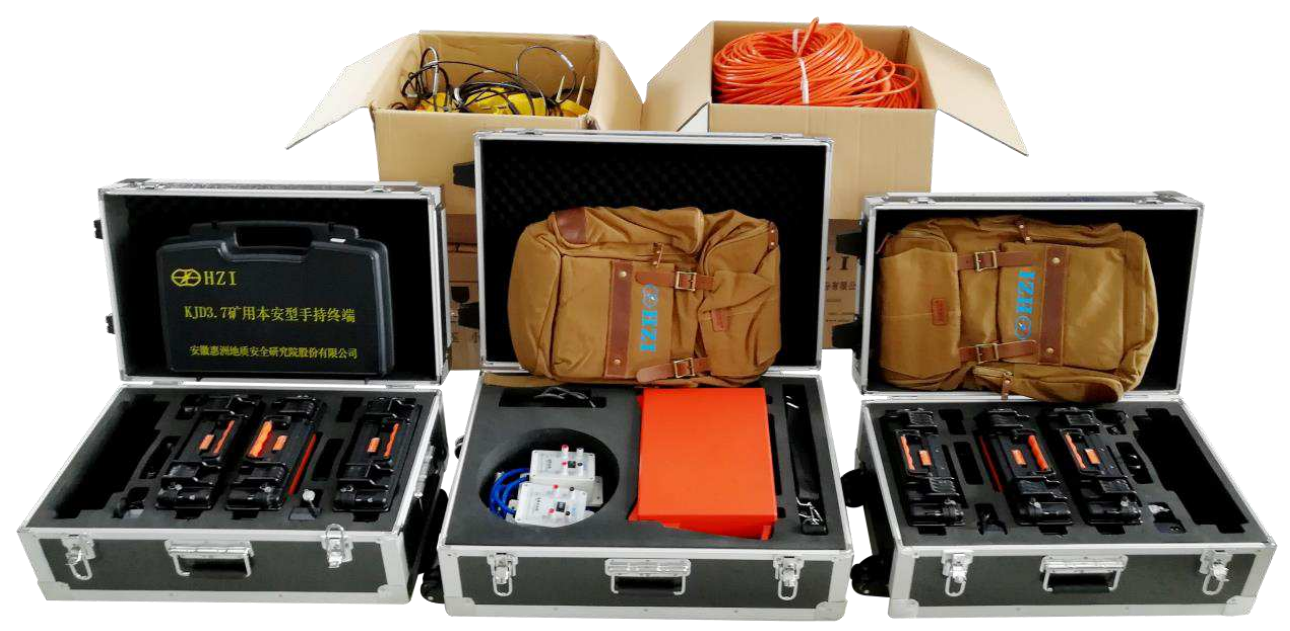




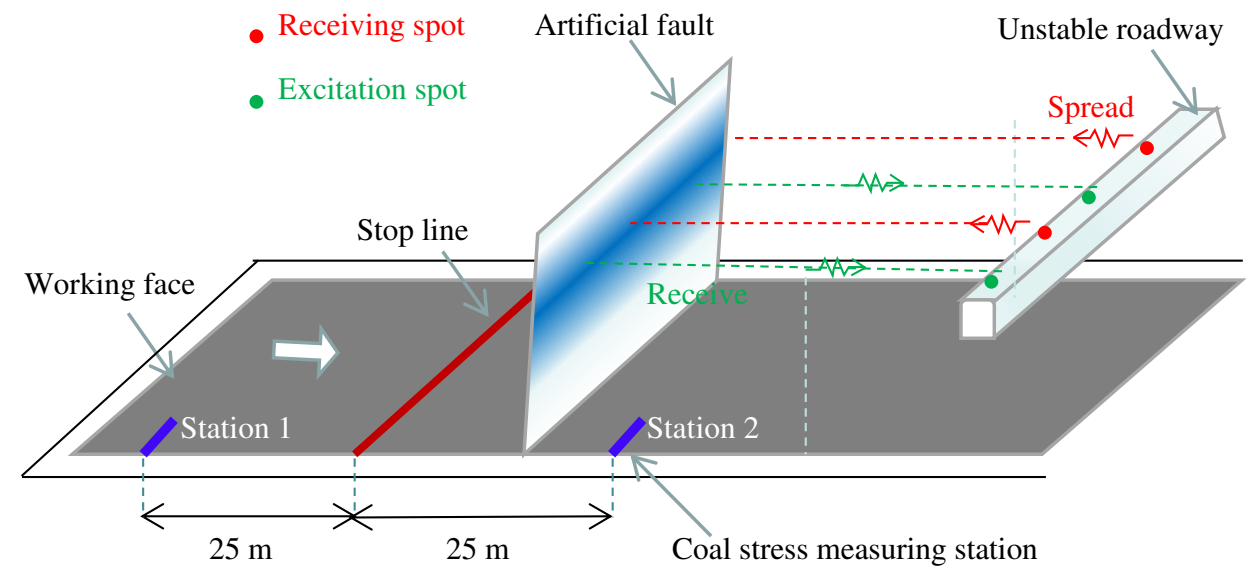

Fig.16. Schematic diagram of station layout

(2) Monitoring of coal stress

Combined with the specific conditions of mine, a total of two Coal stress measuring stations are arranged on the 14200 working face, as shown in Fig.16: Station 1 is located on the left side of blasting borehole, $25 \mathrm{~m}$ away from thedesign stop line, and Station 2 is located on the right side of blasting borehole, $25 \mathrm{~m}$ away from the design stop line $(10 \mathrm{~m}$ away from the pressure relief position). Each measuring station was arranged with three measuring points. The horizontal distance between the three measuring points was controlled within $1 \mathrm{~m}$. The measuring depth of each measuring station is $5 \mathrm{~m}, 10 \mathrm{~m}$, and $15 \mathrm{~m}$, and the measuring hole diameter is $42 \mathrm{~mm}$.

\subsubsection{Analysis of ultrasonic detection results}

The direction of the seismic wave exploration in the mine was the bedding direction. When the integrity of rock strata is good, the change of wave velocity is small. When there is a fault fracture zone in the detection area, the wave velocity will show abnormal changes, and the original data is shown in Fig. 17.

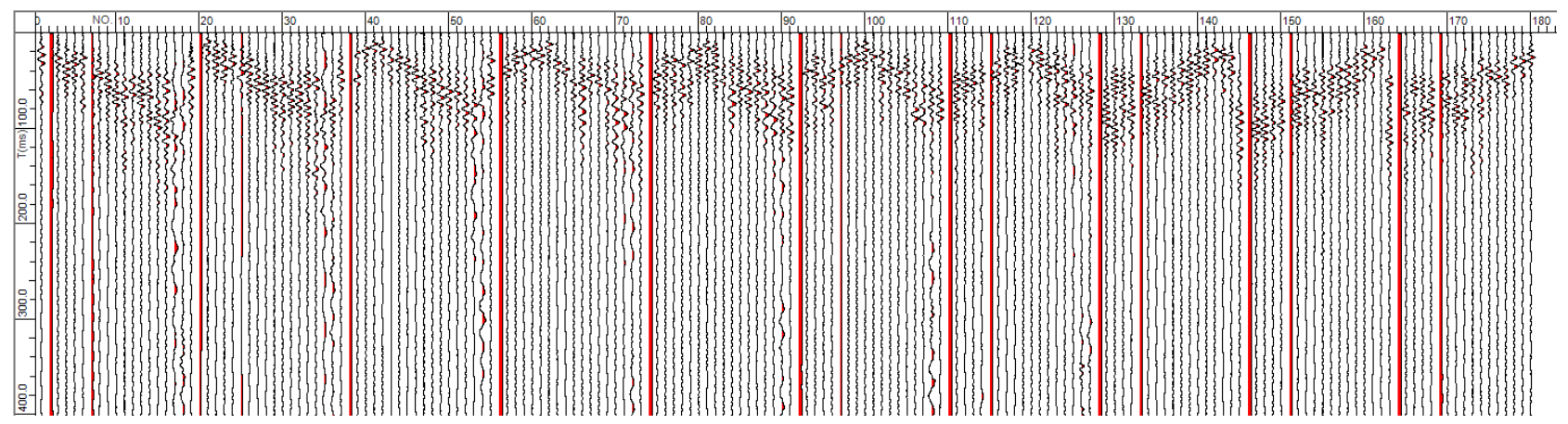

Fig.17. Original waveform of ultrasonic detection

After normalizing the original amplitude data, the artificial fault formed by blasting is 
represented by dark bright spots, as shown in Fig. 18. The width of the artificial fault is about $2.5 \mathrm{~m}$, the middle part is dark red, and the color on both sides gradually becomes lighter. This is because the middle part of the blasting area, the rock damage is more serious, the color is dark red. The two sides are fracture areas, where the rock damage is very small, so the color becomes lighter.

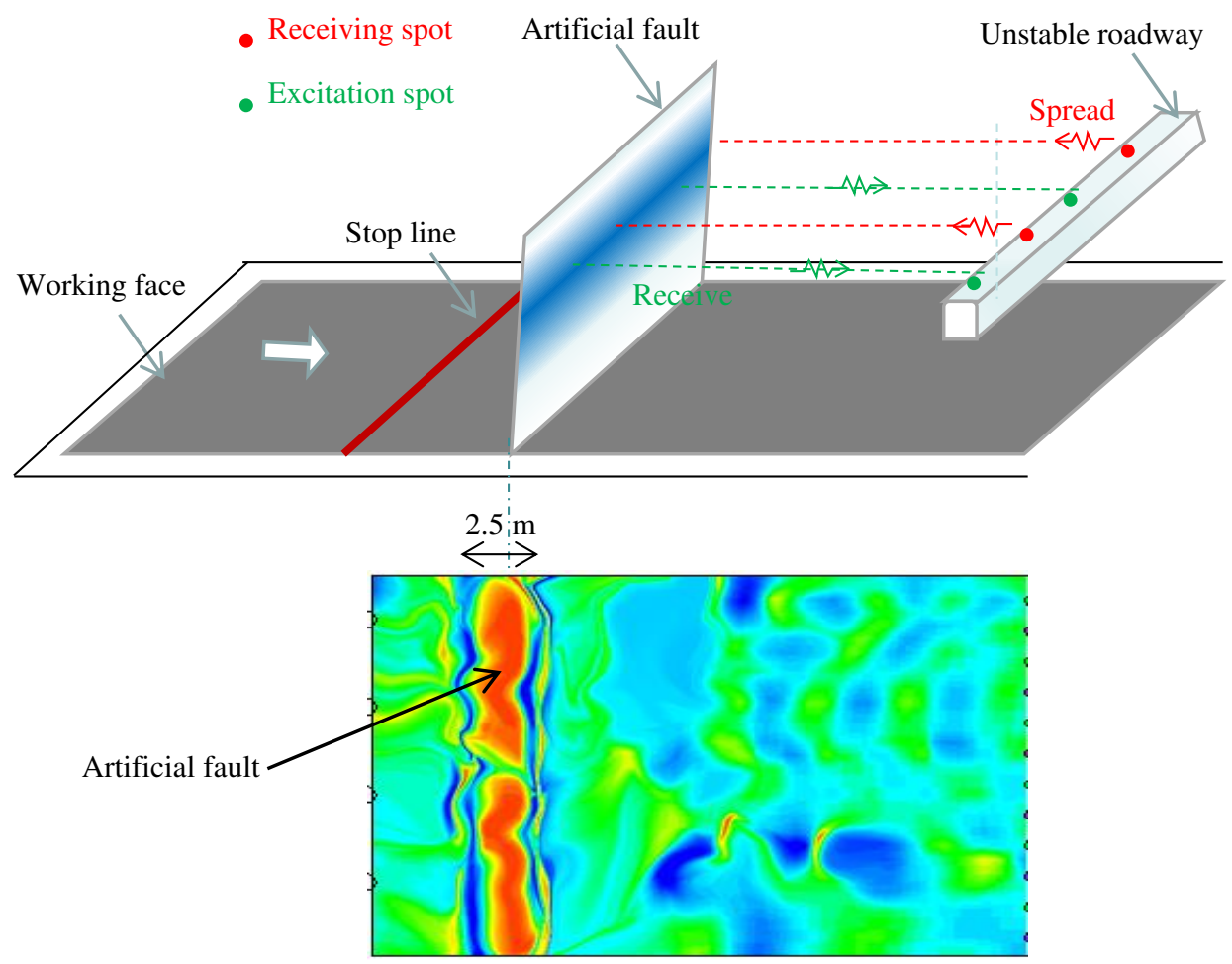

Fig.18. Nephogram of ultrasonic detection

\subsubsection{Analysis of coal stress results}

When the working surface is recovered to a range of $\sim 10 \mathrm{~m}$ from the station, the data shown in the pressure gauge were collected using a data acquisition instrument. According to the measured data, the data of each measuring point were analyzed separately. Combined with the progress schedule of 14200 working face, the working surface was promoted by $4.5 \mathrm{~m}$ per day. The distance from the working station to the measuring station was calculated every day. A scatter plot of pressure gauge pressure over time was obtained, as shown in Fig.19. The influence range of abutment pressure can be calculated by the number of days when the slope of the pressure curve suddenly increases and the advancing rate of working face. 


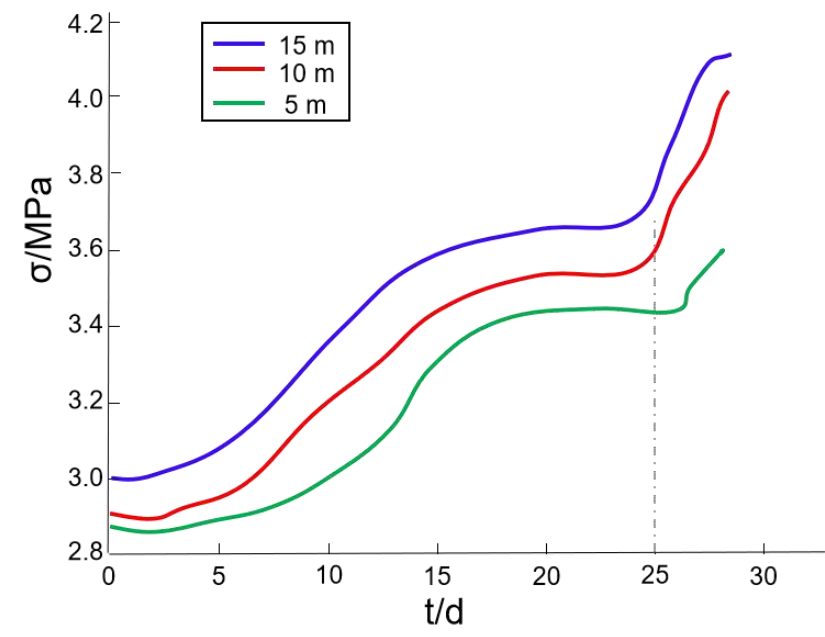

(a)station 1

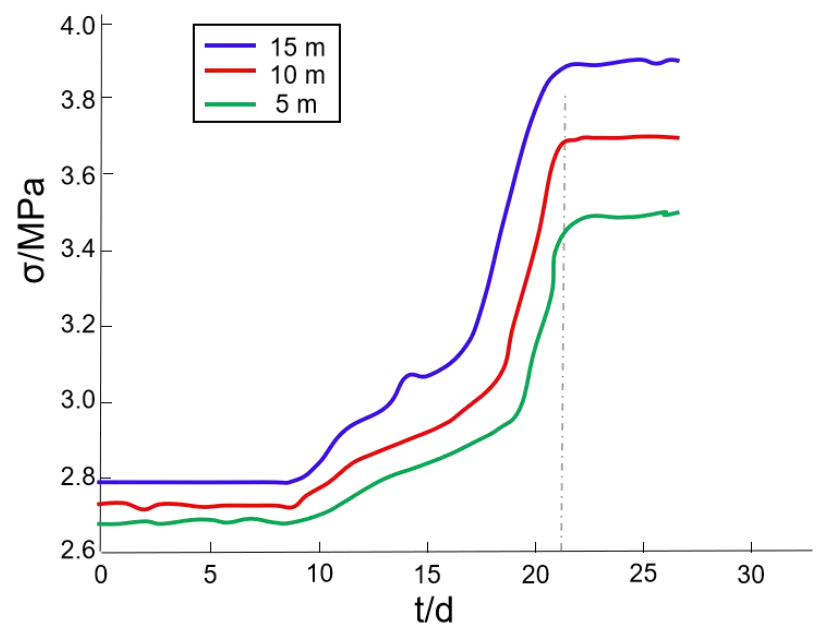

(b) station 2

Fig.19. Pressure curve of each station

Fig.19 (a) shows the pressure change of Station 1. When a stress monitoring system was arranged, the reading of pressure gauge fluctuated slightly and then stabilized. After the stress monitoring system was arranged for three days, the reading of pressure gauge increased slightly. This indicates that the inner wall of borehole was completely in contact with the pressure gauge at this time, and the pressure on the pressure gauge slightly increased. At this time, the working surface advanced for three days. The working face is $116 \mathrm{~m}$ away from the Station 1 . When the working surface was advanced for seven days, the increase in pressure gauge reading is slightly increased compared with the increase after three days. This indicates that the drilling hole entered the influencing range of leading stress, and the drilling is caused by the pressure of coal body at the drilling hole. The deformation increased gradually, so the pressure of pressure gauge increased synchronously until the 16th day after the pressure gauge was placed. The reading of pressure gauge started to increase slowly, indicating that the deformation of borehole became relatively stable. When the working surface was advanced for 25 days, the pressure of pressure gauge started to increase linearly. This indicates that the drilling hole is located near the peak of abutment pressure of working face, and the deformation of drilling hole continued to increase. At this time, the measuring station is $17 \mathrm{~m}$ away from the working surface. In the case of curve, the number of days of pressure increase is 25 days, and the daily footage of working face is $4.5 \mathrm{~m}$. The influencing range of abutment pressure of working face is $129.5 \mathrm{~m}$.

Fig.19 (b) shows the pressure change of Station 2. After the stress monitoring system was arranged for 10 days, the reading of pressure gauge started to increase, indicating that the inner wall of borehole is in full contact with the pressure gauge. At the same time, the pressure on pressure 
gauge slightly increased. At this time, the working surface is $80 \mathrm{~m}$ away from Station 2. After that, the pressure curve continued to rise, and at 21 days after loading the table (the working surface is 30 $m$ away from Station 2), the pressure increased significantly, indicating that the stress peak occurred at this time. Because the working face is stopped at a distance of $25 \mathrm{~m}$ from Station 2, Station 2 failed to measure the overall stress of abutment pressure after blasting. However, according to the above analysis, the effect of abutment pressure after blasting is $80 \mathrm{~m}$.

\section{Conclusion}

This study analyzed the distribution law of stope stress, constructed a new mechanical model for rock mass excavation and pressure relief, elucidated the pressure relief mechanism of rock blasting, and carried out engineering practice. The following conclusions can be drawn:

(1) Using the theory of energy conservation to analyze the principle of pressure transfer after cutting the top of rock, it was found that the total energy of system is constant, composed of rock energy and the accumulated strain energy. The blasting cut causes the fracture zone to deform and destroy a large amount of energy. The accumulated strain energy in the abutment pressure region is released, which in turn reduces the influencing range of abutment pressure.

(2) Based on the pressure transfer principle and stress distribution characteristics around the fault zone, and introducing the coefficient of stress change $K, k$ and $k$ ', a new pressure transfer mechanical model was constructed after blasting and cutting is. The stress mechanism of abutment pressure was analyzed, and an analytical formula was deduced for the mining stress after the crest of rock formation. The results show that the smaller the distance between the cut-off and top of cut-off, the smaller the stress difference on both sides of cut-off within a certain range, but the effect of stop pressure on the working face is less obvious. When the cutting point is closer to the working surface, the higher peak value of abutment pressure is mainly due to the superposition of peripheral stress concentration caused by the cutting and the peak of abutment pressure caused by the mining.

(3) The distribution of the abutment pressure pressure and the deformation of the tunnel before and after the pressure relief were analyzed by numerical simulation. The results show that after the pressure relief, the peak stress area in front of the coal wall disappears and transfers to the area near the pressure relief area, and the stress concentration appears on both sides of the blasting pressure relief area. After blasting and pressure relief, the influence range of the advance bearing stress 
495

496

497

498

499

500

501

502

503

504

505

506

507

508

509

510

511

512

513

514

515

516

517

518

519

520

521

decreased obviously, and the stress concentration around the tunnel was not obvious. The displacement of roof and floor is $29.7 \mathrm{~cm}, 66.4 \%$ less than that before pressure relief, and the displacement of two sides is $31.4 \mathrm{~cm}, 69.8 \%$ less than that before pressure relief. It can be seen that blasting pressure relief can effectively control the deformation of the tunnel in front of the work.

(4) The results of ultrasonic detection show that the artificial fault zone was well formed, the width of the fault zone was about $2.5 \mathrm{~m}$, the damage in the middle was serious, and the damage on both sides is reduced. The results of coal stress test show that the influencing range of abutment pressure of working face before blasting pressure relief is $129.5 \mathrm{~m}$. The influencing range of abutment pressure after blasting pressure relief is $80 \mathrm{~m}$. This is $49.5 \mathrm{~m}$ shorter than the pressure before the pressure relief, which is reduced by nearly $1 / 3$, shortened from the previous $150 \mathrm{~m}$ to 90 $\mathrm{m}$. Therefore, rock blasting pressure relief can effectively shorten the influencing range of abutment pressure of working face. The application of blasting pressure relief tunnel technology has great significance to reduce the coal pillar size of tunnel and improve the mine recovery rate and dynamic pressure tunnel deformation control.

\section{Compliance with ethical standards}

This work is supported by the State Key Laboratory for Geomechanics and Deep Underground Engineering, China University of Mining \& Technology, Beijing (No. SKLGDUEK1928), the National Natural Science Foundation of China (No. 51674265) and Project funded by China Postdoctoral Science Foundation (No. 2020T130702), which are gratefully acknowledged.

\section{Conflict of interest}

The authors declare that they have no conflict of interest.

\section{Data Availability:}

The manuscript data used to support the findings of this study are available from the corresponding author upon request. 


\section{Reference}

Qian MG, Shi PW, Xu JL. Mine pressure and strata control. China University of mining and Technology Press. 2010

He MC, Xie HP, Peng SP, et al. Study on rock mechanics of deep mining. Journal of rock mechanics and engineering. 2005; 12:2803-2813.

Guo C. Study on the evolution of Mining pressure and its influence on tunnel deformation based on the key layer theory . PhD thesis. The China: China University of mining and technology. 2018.

Grady D.E., Kipp M.L. Continuum Modeling of Explosive Fracture in Oil Shale. Int.J.Rock Mesh.Sci\&Geomech.Abstr. 1987; 17:147-157.

Taylor L.M., Chen E.P., Kusmaul J.S. Microcrack_induced accumulation in brittle rock under dynamic loading. Computer Method in applied mechanics and engineering. 1986; 55:301-320.

Kuszmaul J.S. New Constitution Model for Fragmentation of Rock under Dynamic Loading. Sympom Rock Fragment by blasting. 1987:412-423.

Throne B.J. Experimental and Computational Investigation of thefundamental Mechanics of Cratering. Sympom Rock Fragment byblasting. 1990:117-124.

Gao MZ, Jin WC, Dai ZX et al. Relevance between abutment pressure and fractal dimension of crack network induced by mining. International Journal of Mining Science and Technology. 2013; 23:925-930.

Li HM, Xiong ZQ, Li DY et al. Research on evolution of mining pressure field and fracture field and gas emission features. Engineering Sciences. 2012;10:49-55.

Meng QB, Han LJ, Chen YL et al. Influence of dynamic pressure on deep underground soft rock tunnel support and its application. International Journal of Mining Science and Technology. 2016; 26:903-912.

Wang LG, Song Y, He XH et al. Side abutment pressure distribution by field measurement. Journal of China University of Mining and Technology. 2008(04):527-530.

Zhang Y, Zhang XB, Xu LF et al. Formation and evolution of gas flow channels in the abutment pressure area. International Journal of Mining Science and Technology. 2012; 6:801-807.

Zhang JF, Jiang FX, Zhu ST et al. Width design for gobs and isolated coal pillars based on overall burst-instability prevention in coal mines. Journal of Rock Mechanics and Geotechnical Engineering. 2016; 4:551-558.

Zhang HL, Wang LG, Sun J. Distribution of lateral floor abutment pressure in a stope. Mining Science and Technology. 2011; 21:217-221.

$\mathrm{Xu} \mathrm{XD}, \mathrm{He} \mathrm{MC}$, Zhu $\mathrm{C}$ et al. A new calculation model of blasting damage degree-Based on fractal and tie rod 
damage theory. Engineering Fracture Mechanics. 2019; 220:106619.

Jiang HJ, Cao SG, Zhang Y et al. Analytical solutions of hard roof's bending moment, deflection and energy under the front abutment pressure before periodic weighting. International Journal of Mining Science and Technology. 2016: 26:175-181.

Zhang HG, Miao XX, Zhang GM et al. Non-destructive testing and pre-warning analysis on the quality of bolt support in deep tunnels of mining districts.International Journal of Mining Science and Technology. 2017; 27:989-998.

Liu XQ, Zhang GF. Technology of cutting top and relieving pressure to keep tunnel along goaf in soft and broken surrounding rock. Coal science and technology. 2013; 2:133-134.

$\mathrm{Pu}$ WL, Zhang GH. Research on key technology of driving along goaf with directional fracture, roof cutting and pressure relief narrow coal pillar. Industrial safety and environmental protection. 2014; 5: 45-47

Wan HX, Zhang K, Chen DD, et al. Roof cutting and pressure relief gob side entry retaining technology of Jiaozishan mine. Coal mine safety. 2014; 12: 85-88.

Wang WW, Li FY, LAN YW. Research and application of roof cutting and pressure relief gob side entry retaining technology. Journal of Heilongjiang University of science and technology. 2014; 1: 20-23.

Tang CJ, Sheng JF. Research and application of roof cutting and pressure relief tunnel protection technology. Coal technology. 2015.

Chen Y, Hao SP, Chen Yantao, et al. Study on the application of shallow hole blasting with pilot hole in the pressure relief of cutting top of retaining tunnel. Journal of mining and safety engineering. 2015; 32: 253-259

He MC, Song ZQ, Wang A et al. The theory of roof cutting and short wall beam in longwall mining and its 110 construction method -- the third mining science and technology revolution. Coal science and technology. 2017; 1: $1-9$.

Meng ZP, Peng SP, Feng Y et al. The influence of fracture structure on the pressure and roof stability of mining face. Coalfield geology and exploration, 2006; 3: 24-27.

Lv ZF, Meng ZP. Characteristics of pores and fractures in coal seams near normal faults and their research significance. Coalfield geology and exploration. 1989; 6: 29-33

Yu GG, Xie HP. Numerical simulation of fractal interface effect of mining fault activation. Journal of coal industry. 1998; 4: 396-400.

Li ZH, Dou LM, Chen GX, et al. Study on the risk of fault rock burst under the influence of mining. Journal of China University of mining and technology. 2010; 4:490-495.

Li FQ, Sun SZ, Li LJ. Geostrain of North China and banglu fault zone. Journal of petrology and engineering. 1982; 

$1: 74-86$.

584 Ding XC, Li LJ, Liang HQ. Principle and application of in-situ stress measurement. Beijing: Geological 585 Publishing House, 1981:131-141.

586 Su SG. Influence of fault structure on in-situ stress field and its engineering significance. Journal of rock 587 mechanics and engineering. 2002; 2:296-296.

588 Mehravar M., Harireche O., Faramarzi A. and Alani A.M. (2017), Modelling the variation of suction pressure 589 during caisson installation in sand using flac3d. Ships Offshore Struc. 2017; 12:893-899.

590 Kabwe E., Karakus M. and Chanda E.K. Creep constitutive model considering the overstress theory with an $591 \quad$ associative viscoplastic flow rule. Comput Geotech. 2020;124.103629. 


\section{Figures}

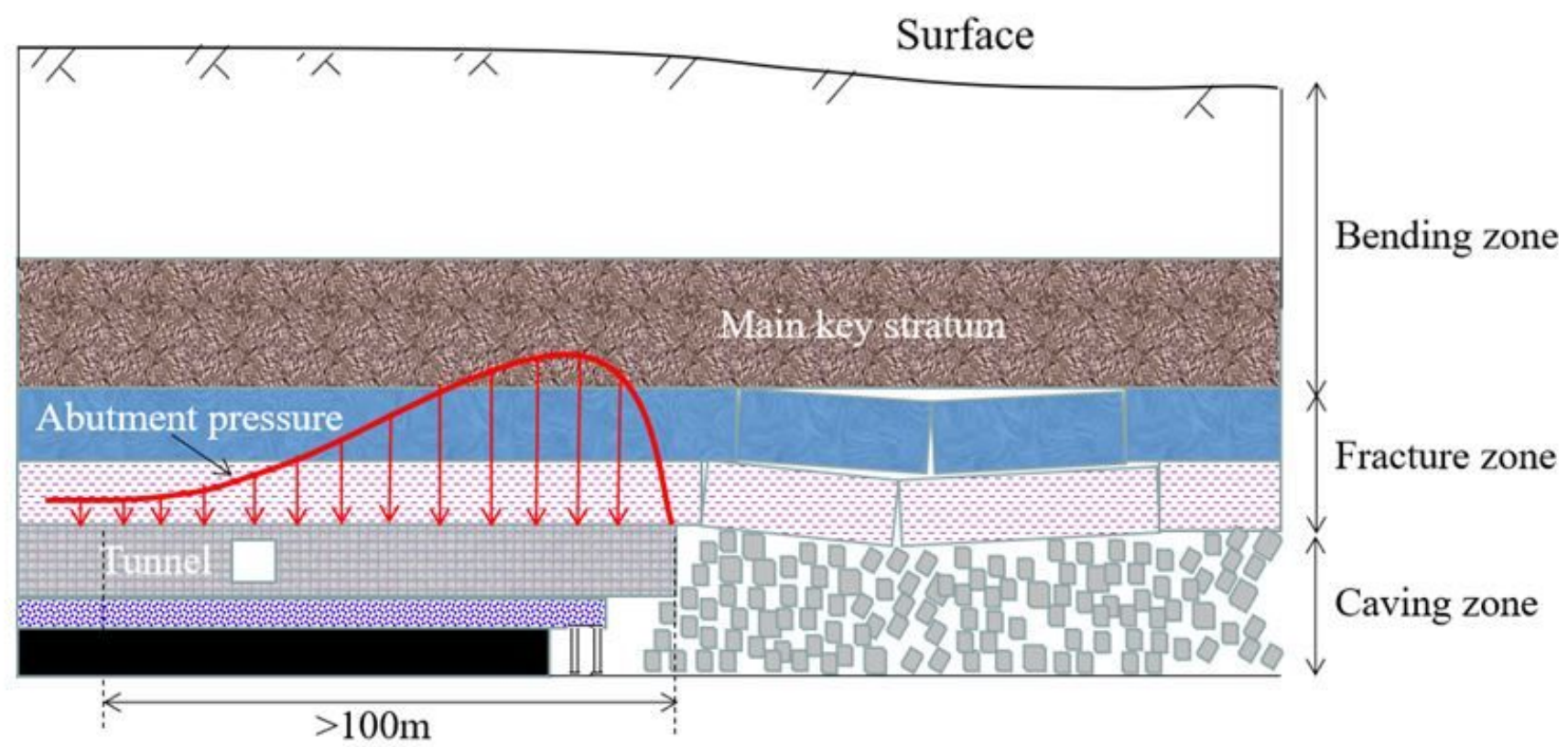

Figure 1

General information of the working face
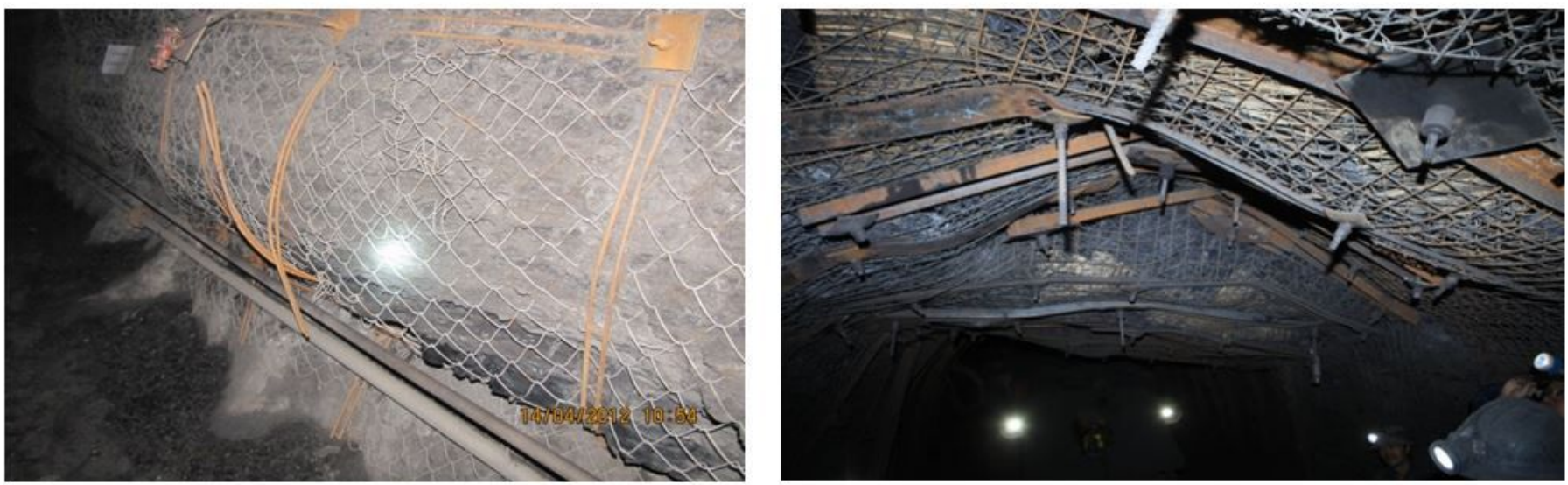

Figure 2

Tunnel deformation under dynamic pressure 


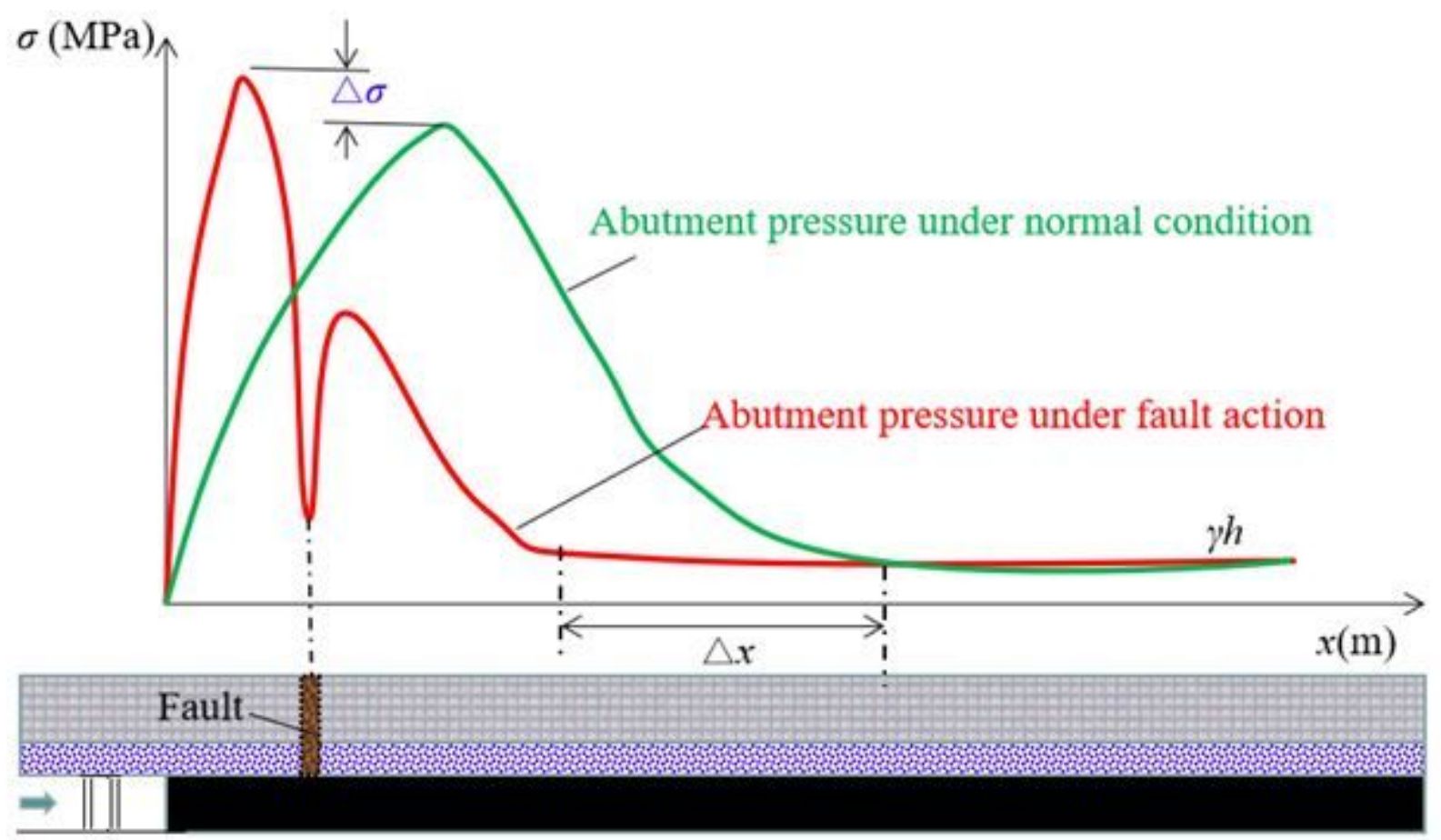

Figure 3

Diagram of stress distribution under the influence of faults

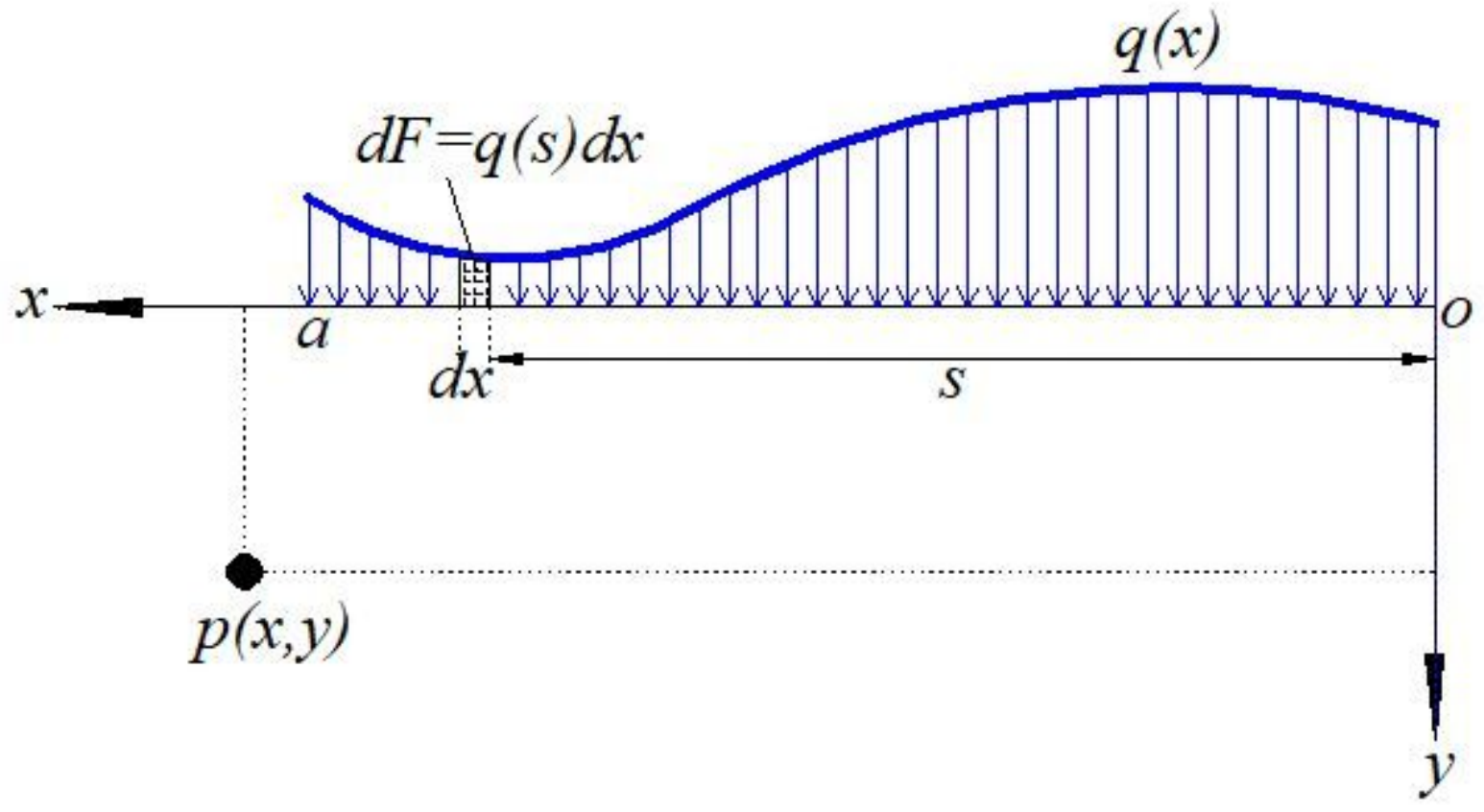

Figure 4 


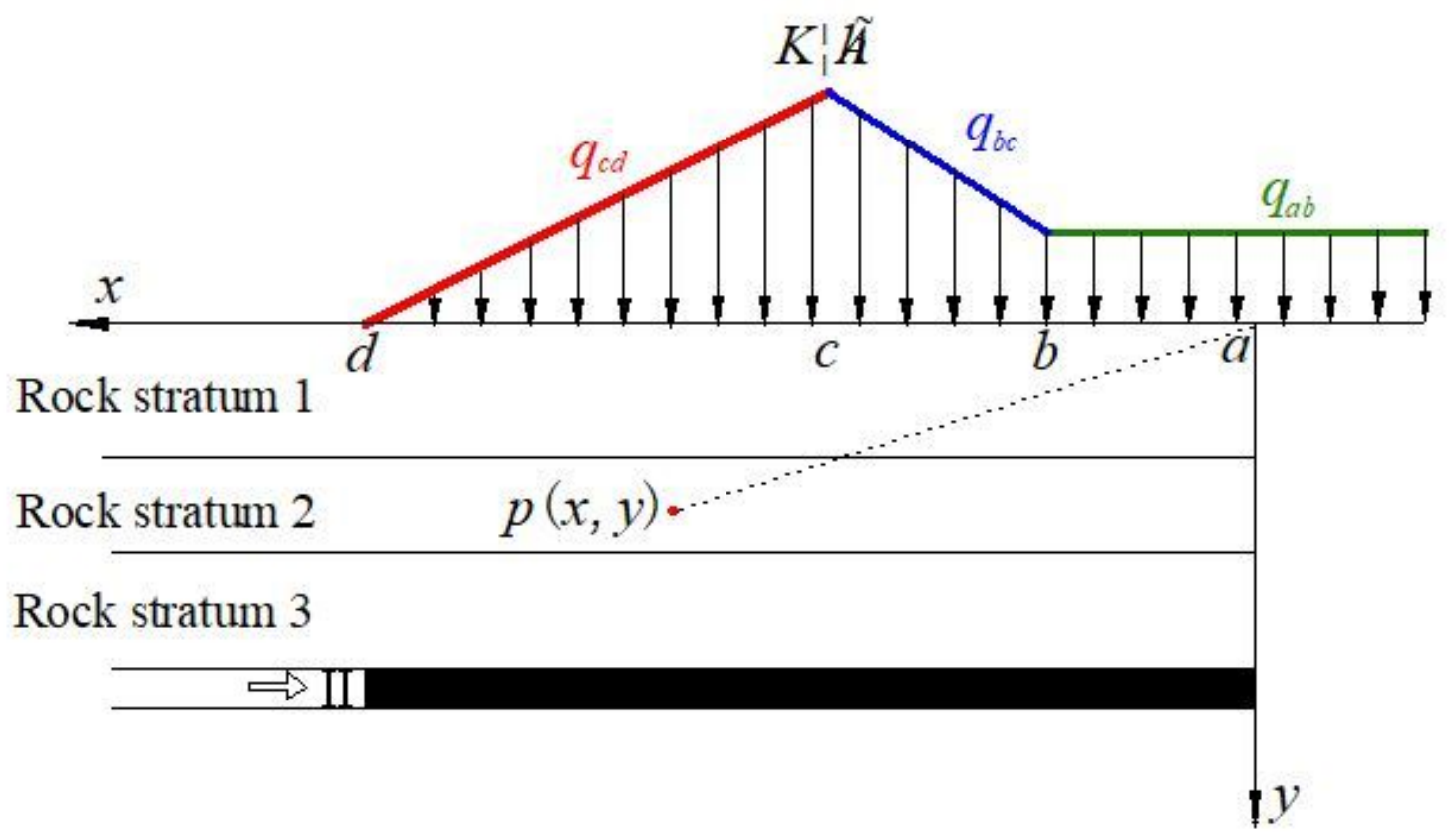

Figure 5

The calculation model of abutment pressure transferring

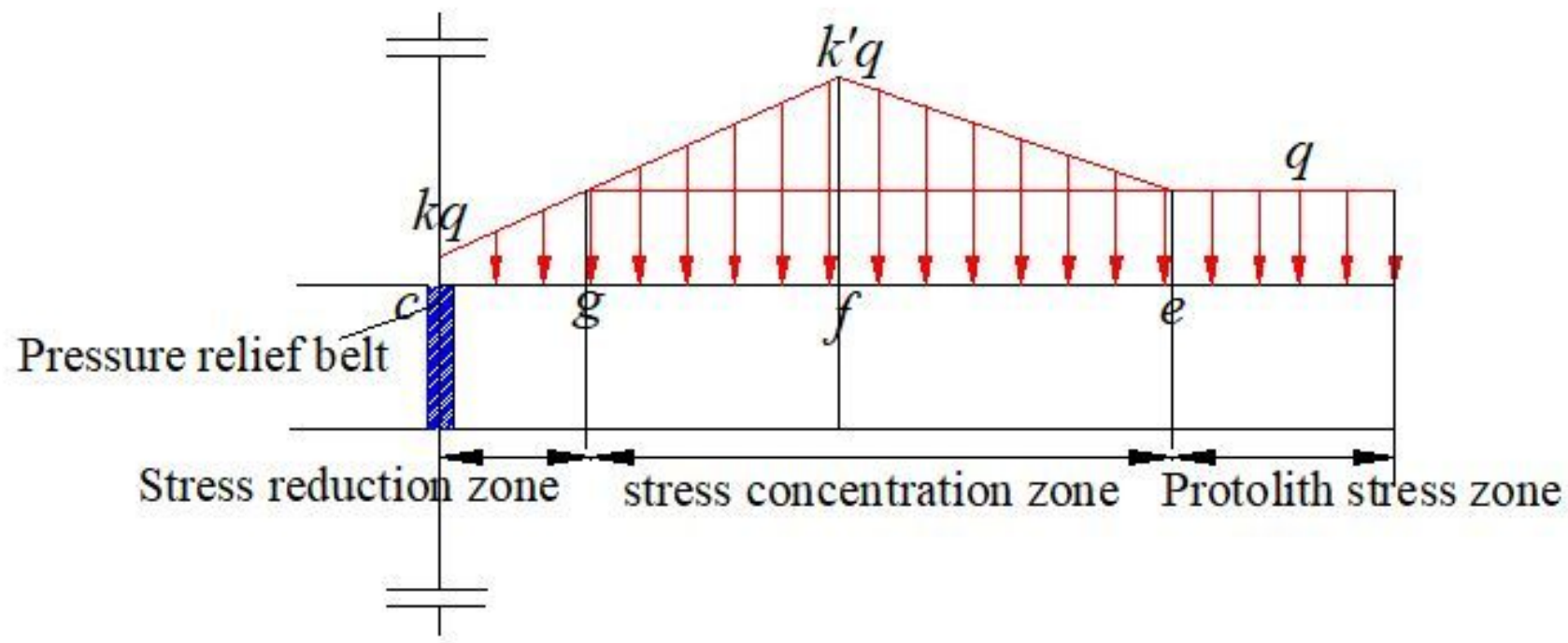

Figure 6

Mechanical model of stress distribution on both sides of artificial fault 


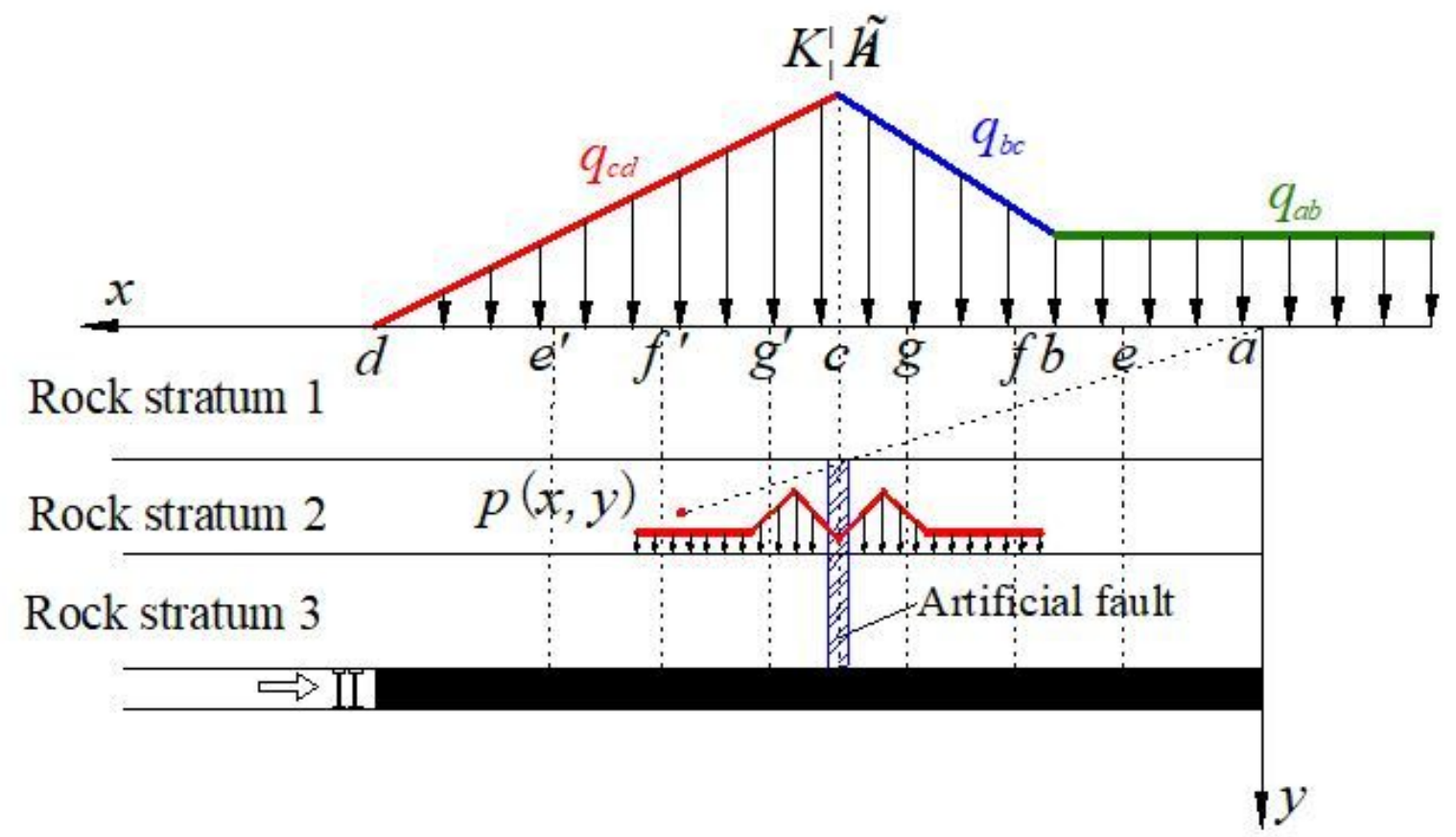

Figure 7

Calculation model of arbitrary point force of bearing stress with artificial fault

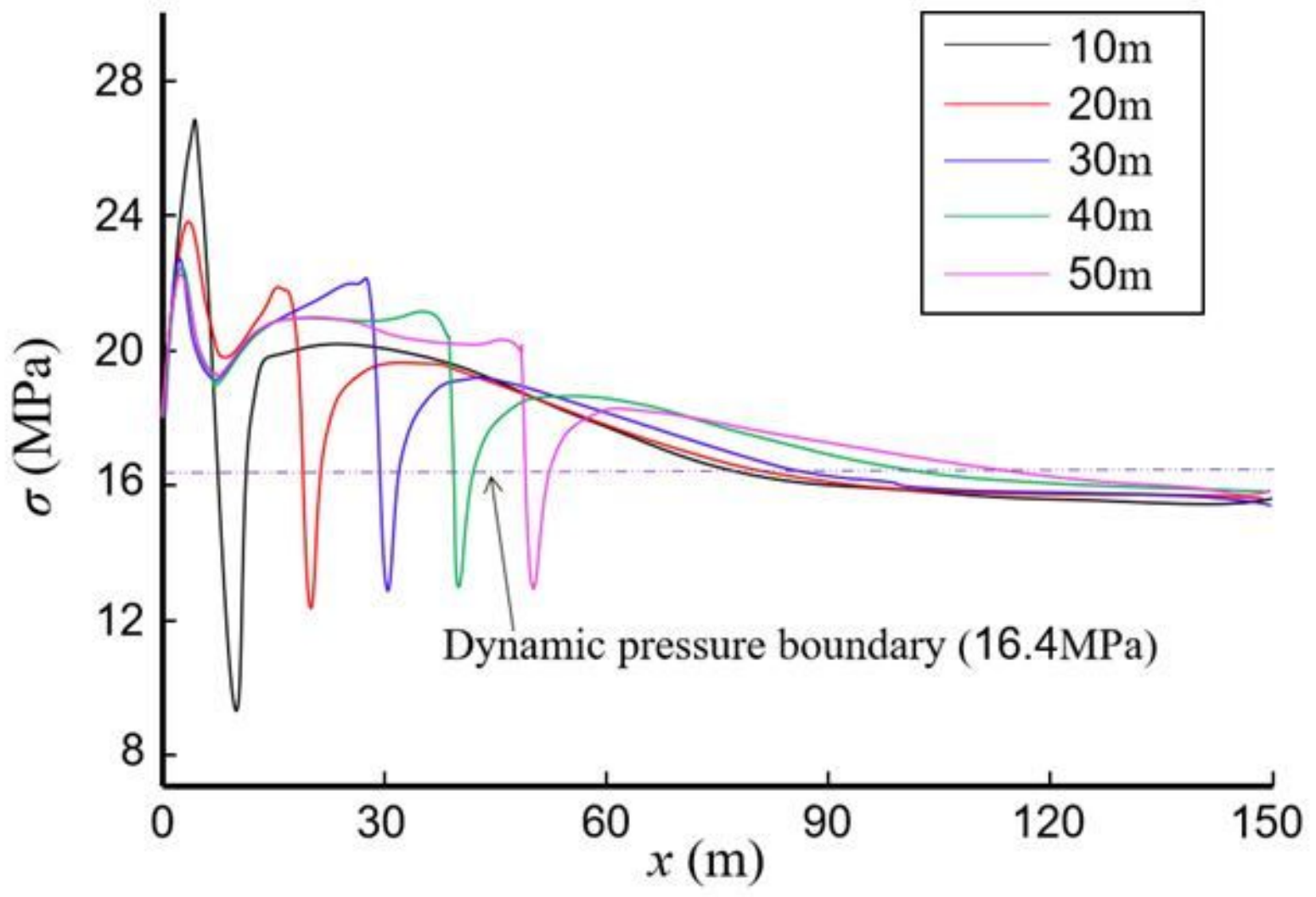




\section{Figure 8}

Abutment pressure curves at different horizontal cutting positions from the working face

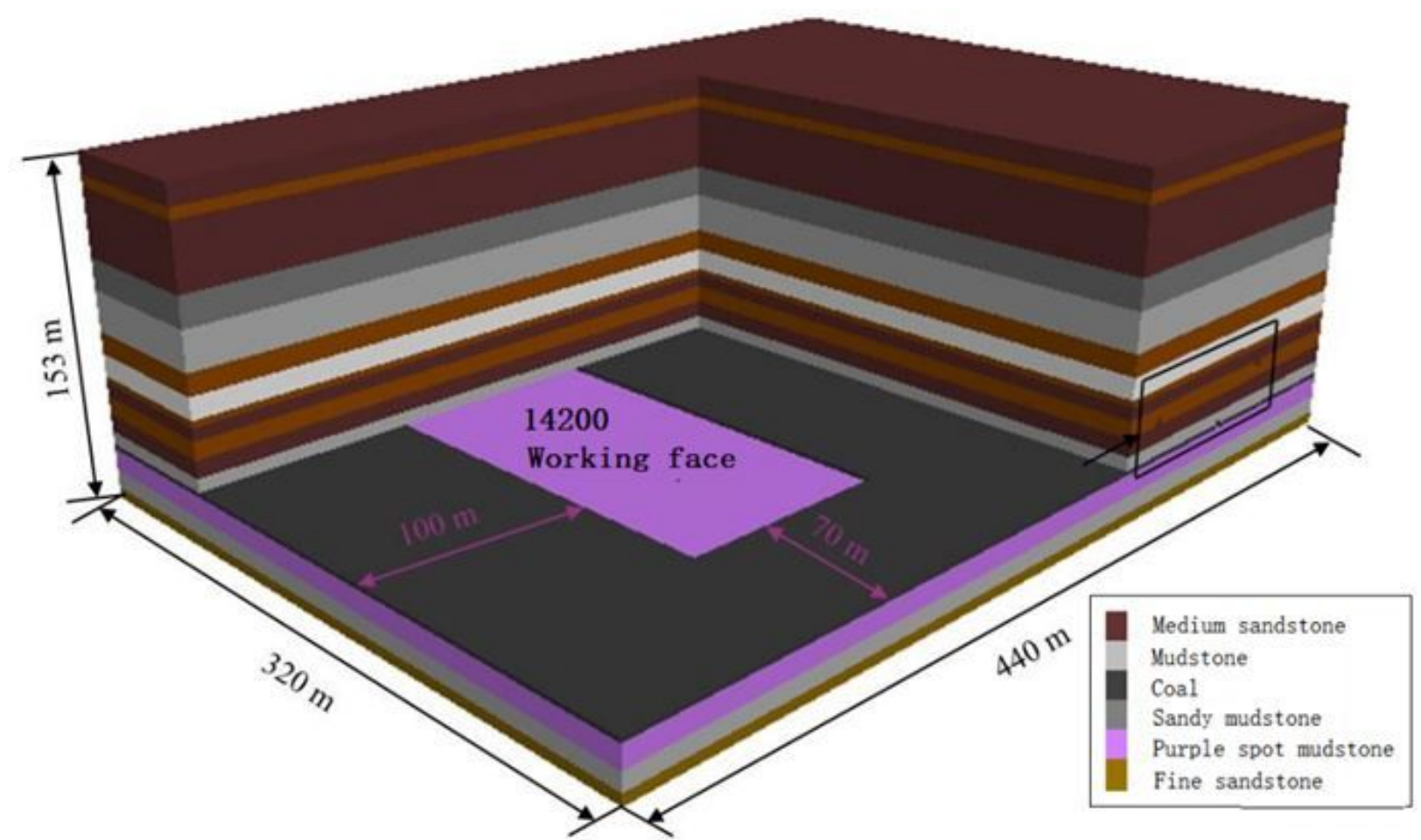

\section{Figure 9}

Numerical model of the strata

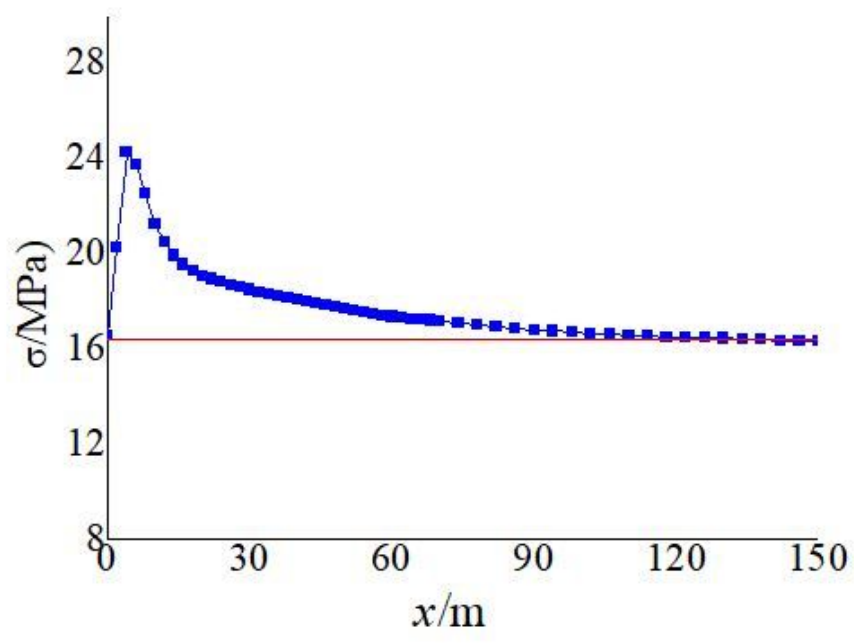

(a) Before unloading

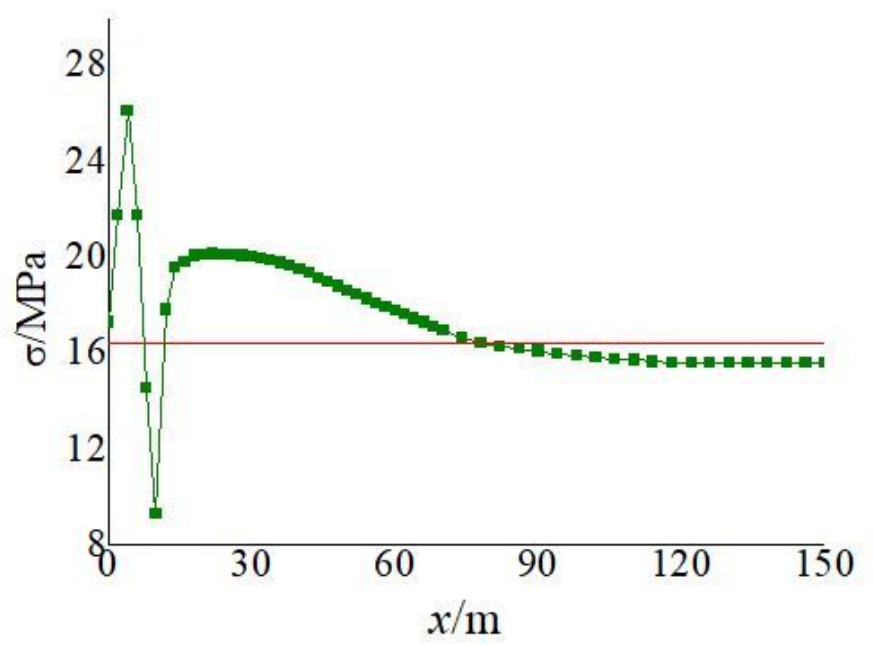

(b) After unloading 
Abutment pressure curve before and after pressure relief

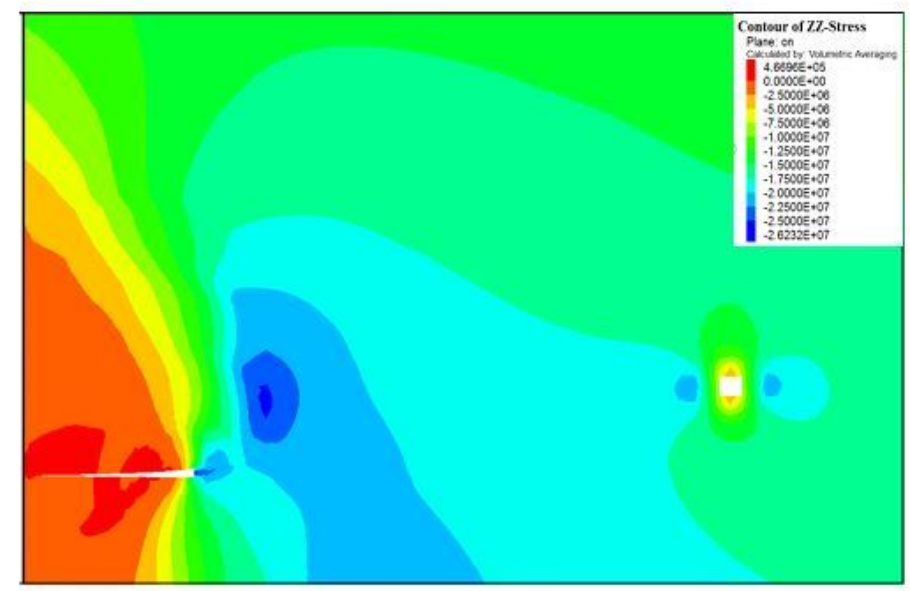

(a) Before unloading

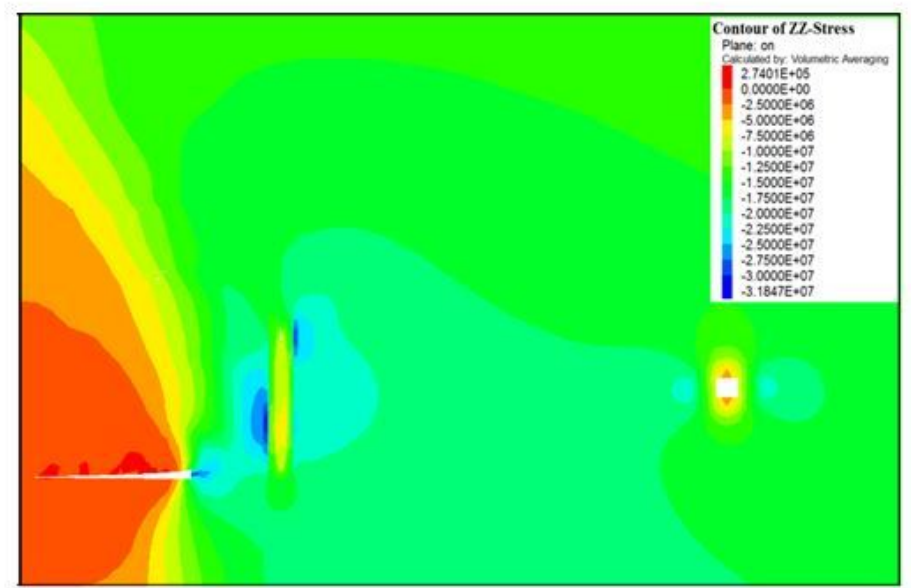

(b) After unloading

\section{Figure 11}

Vertical stress cloud diagram before and after pressure relief

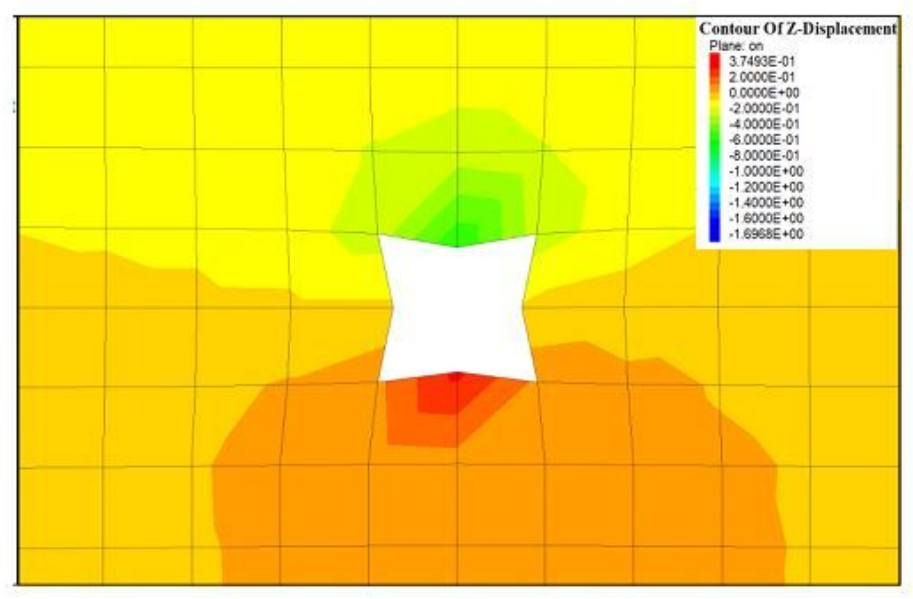

(a) Before unloading

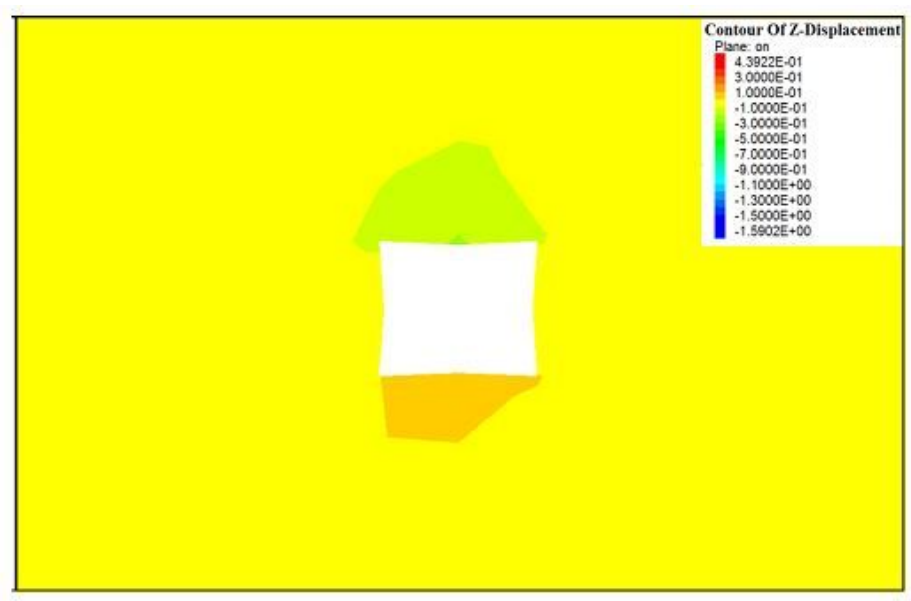

(b) After unloading

\section{Figure 12}

tunnel displacement cloud map before and after blasting pressure relief 


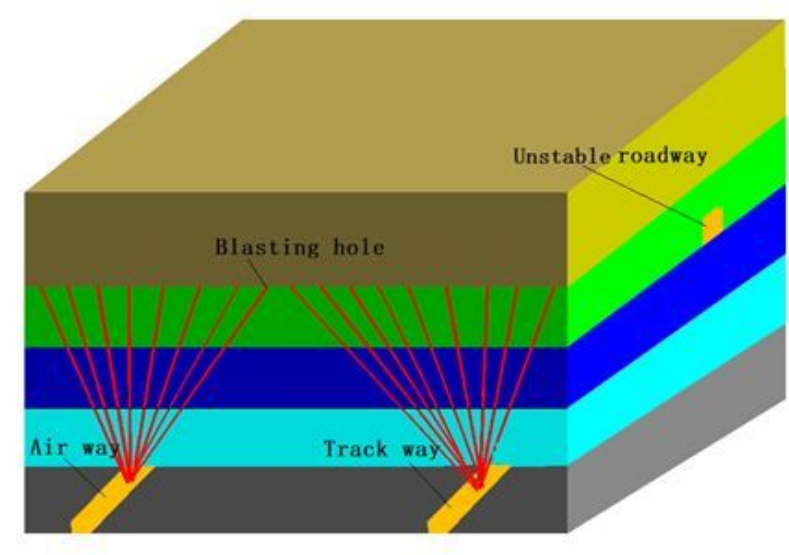

(a) 3D diagram

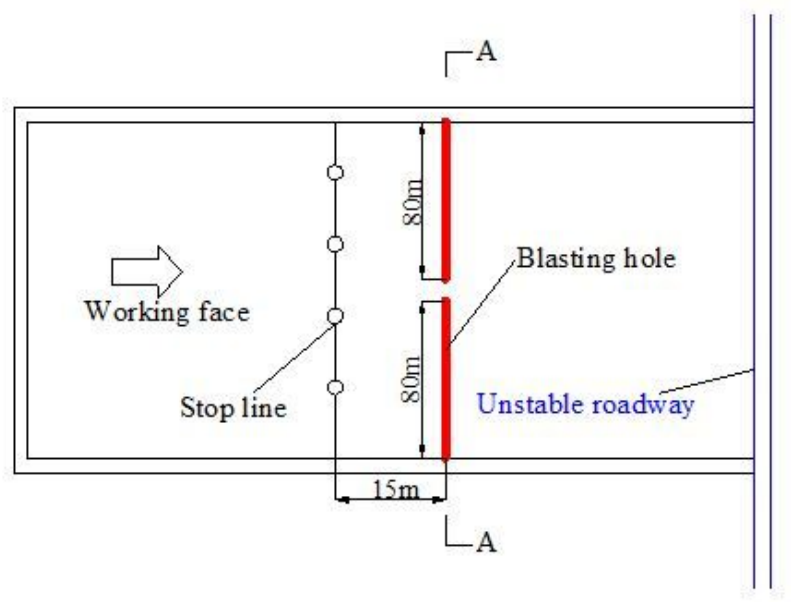

(b) 2D diagram

\section{Figure 13}

Layout of blastholes

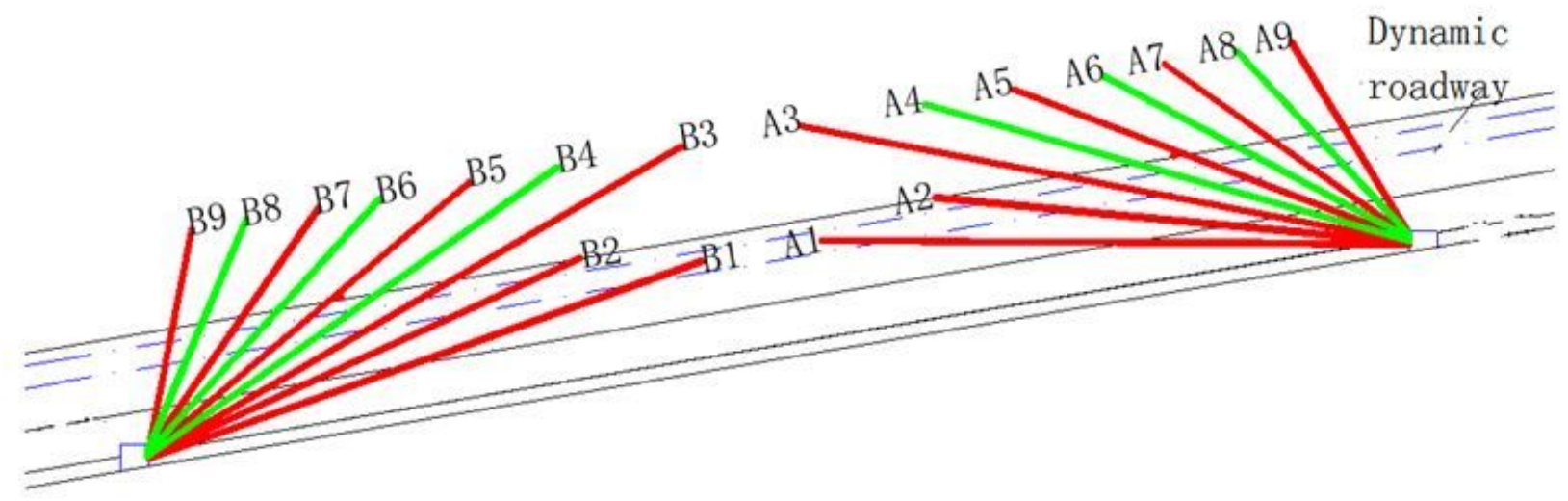

Figure 14

A-A section 


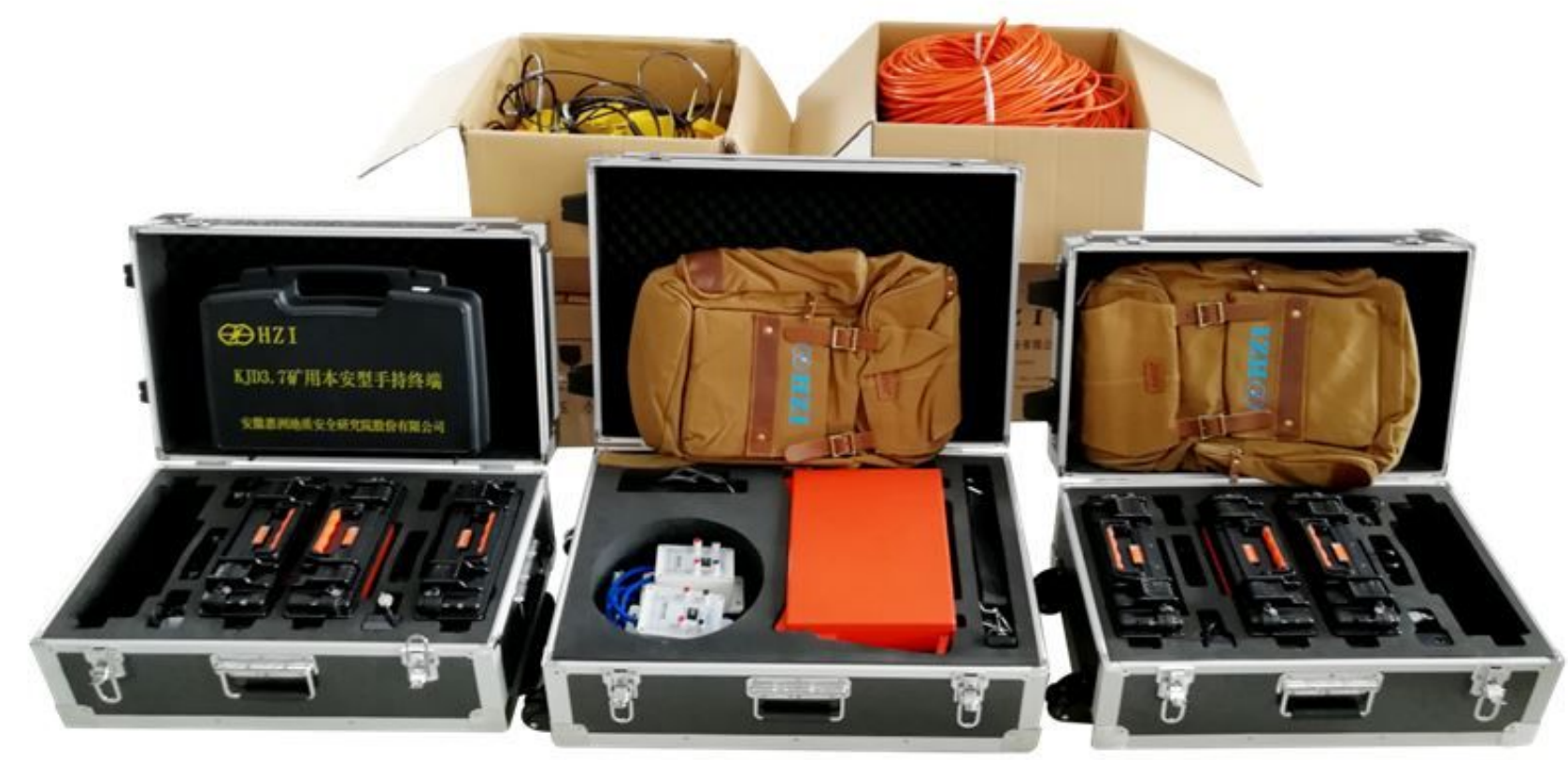

Figure 15

Ultrasonic detection system

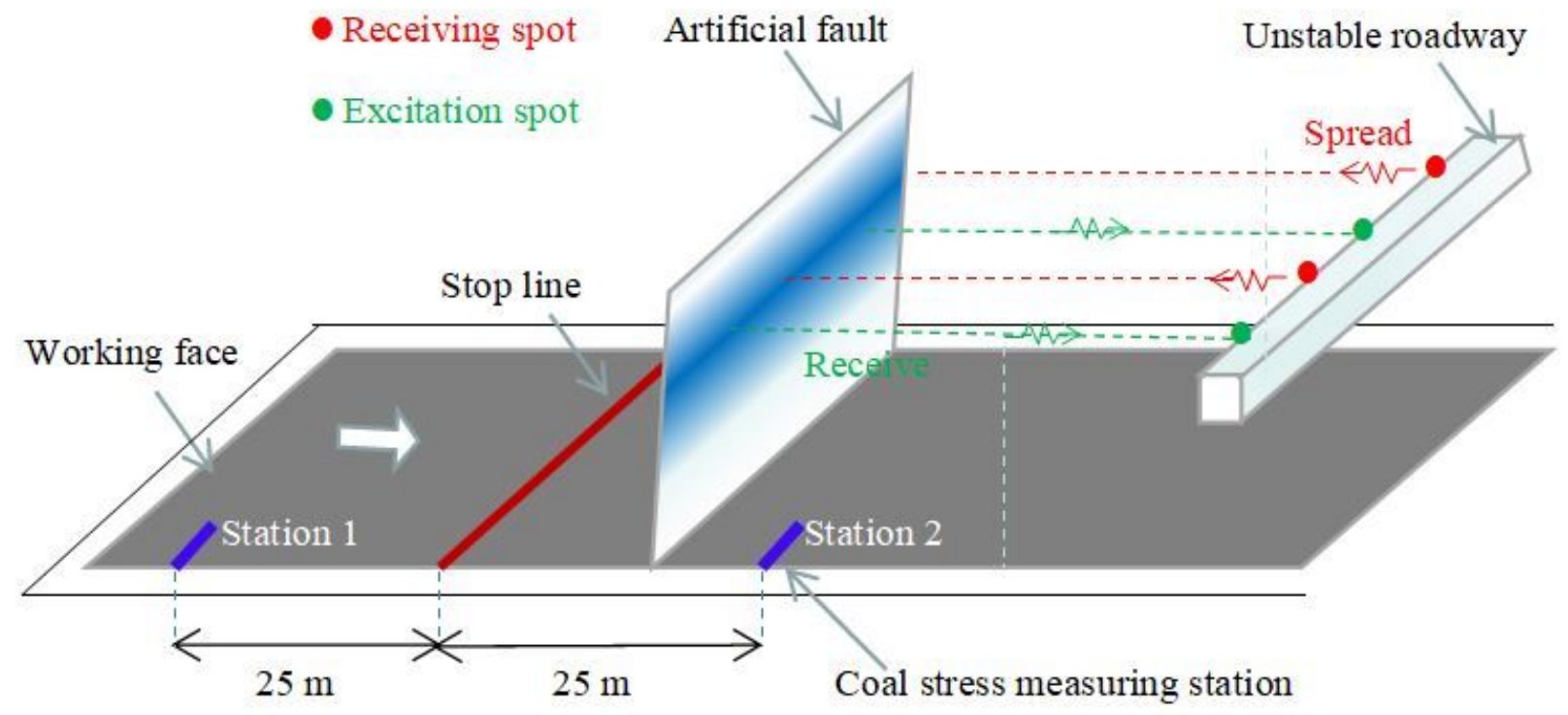

Figure 16

Schematic diagram of station layout 


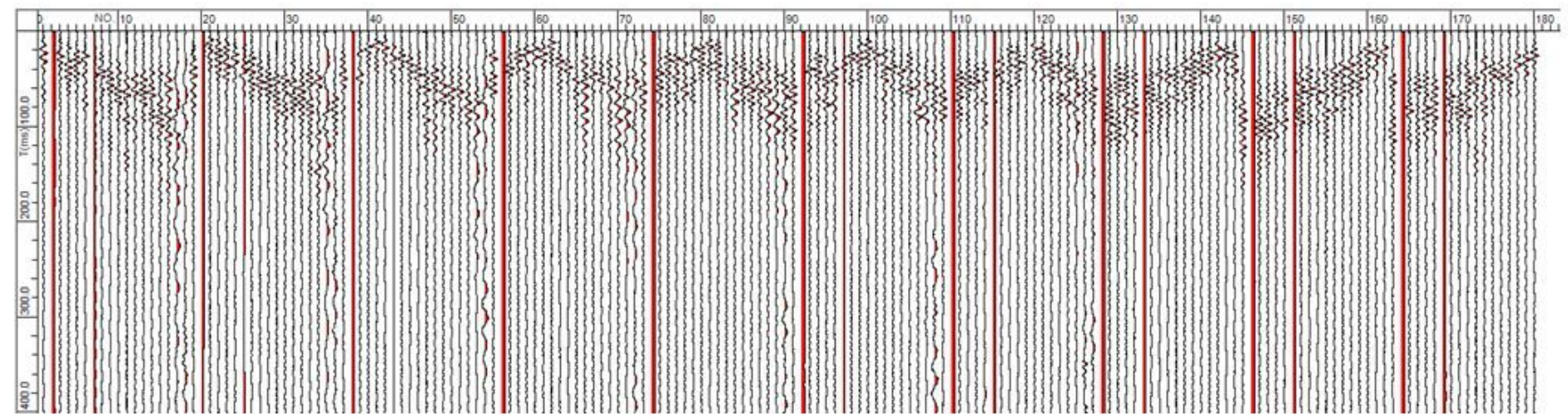

Figure 17

Original waveform of ultrasonic detection

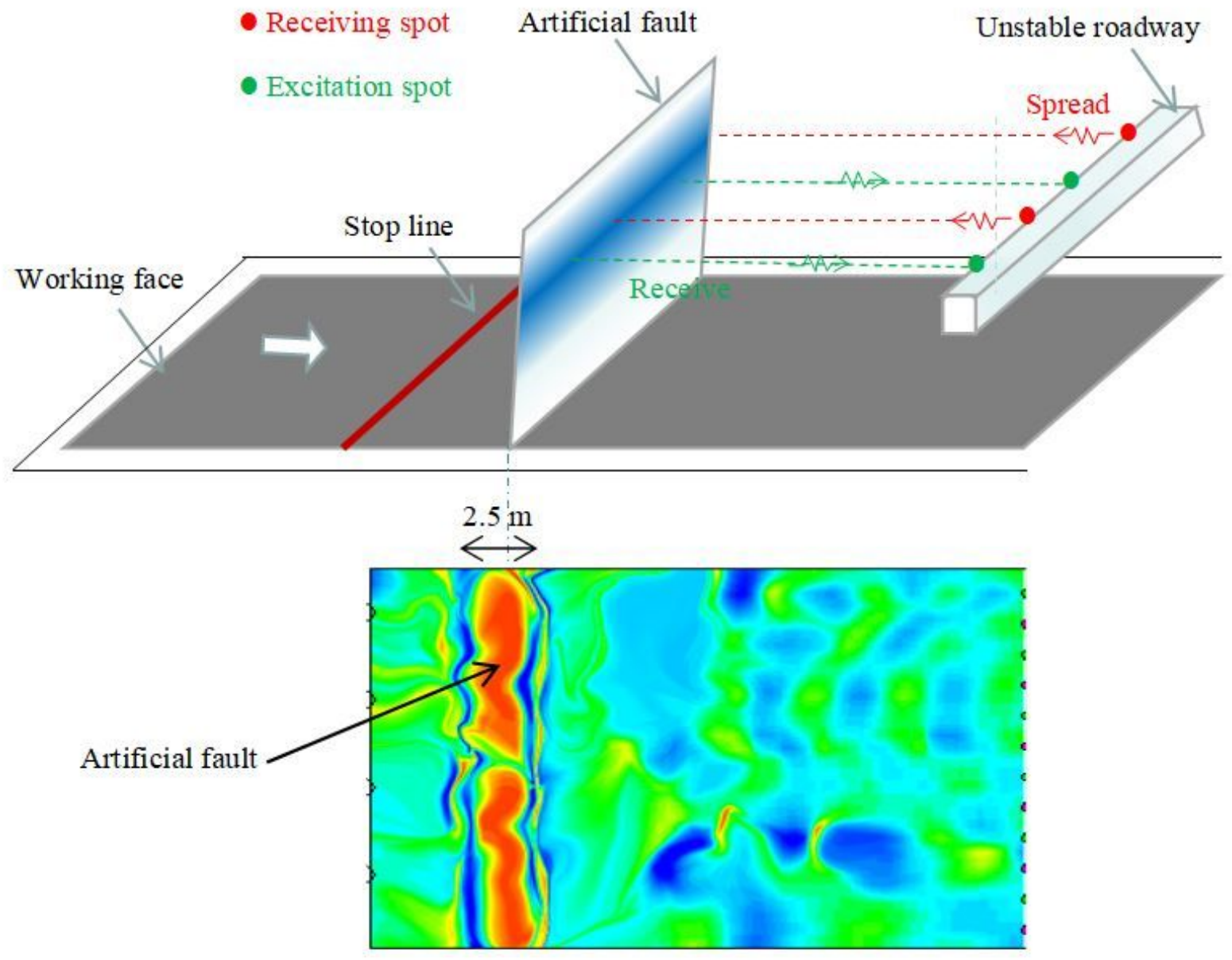

Figure 18

Nephogram of ultrasonic detection 


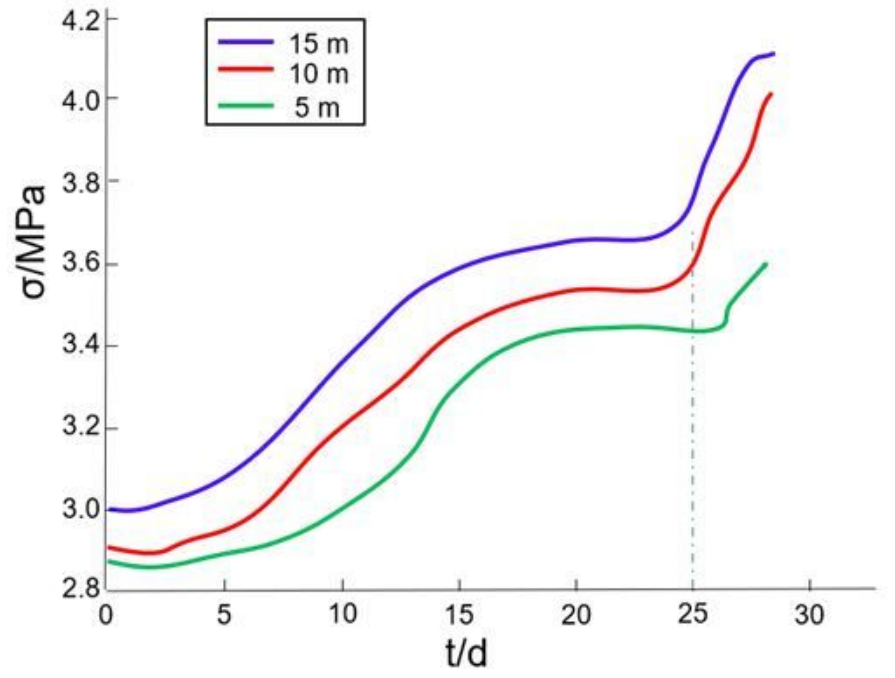

(a)station 1

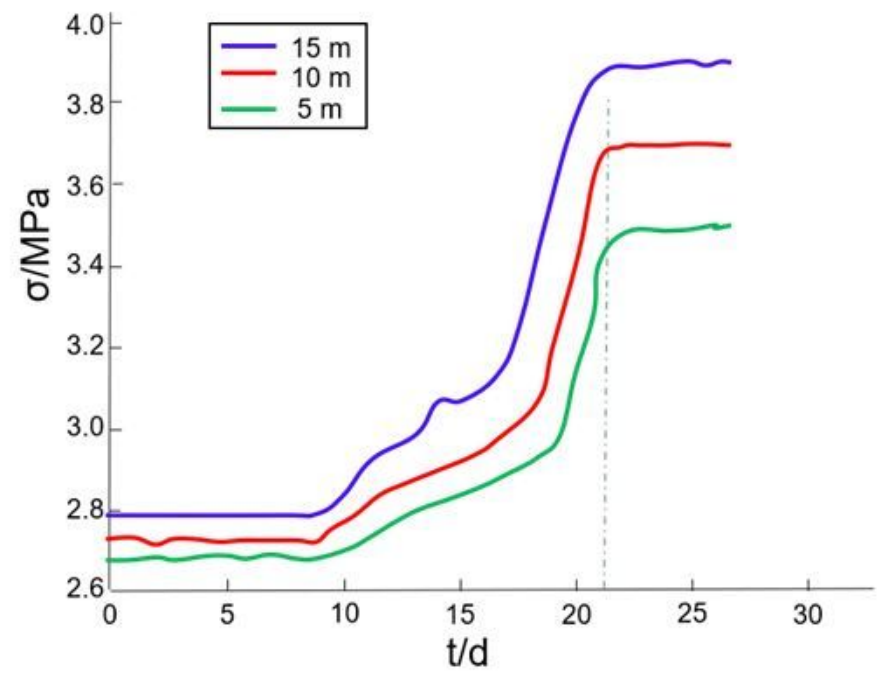

(b)station 2

Figure 19

Pressure curve of each station 